\title{
La influencia del Área Intermedia durante la época prehispánica en la zona que comprende el actual territorio salvadoreño
}

\section{The influence of the Central Area during the prehispanic period in the present salvadorean territory}

\author{
Margarita Morán' \\ Francisco Alvarado 2 \\ Carlos Flores-Manzano ${ }^{3}$ \\ Krishnangi Ramírez ${ }^{4}$ \\ Universidad Tecnológica de El Salvador \\ margara.moran@gmail.com
}

Recibido: 21/07/17 - Aceptado: 20/10/17

\section{Resumen}

El actual territorio salvadoreño se encuentra localizado en un área geográfica privilegiada para comprender la dinámica entre el Área Intermedia y Mesoamérica, debido a esto, facilita el acceso al océano Pacífico y es un corredor terrestre entre las actuales Norte y Suramérica, por eso es crucial determinar la influencia que sufrieron las culturas que convivieron con el Área Intermedia, y determinar su reflejo tanto en la cerámica como en la mitología y la escultura. Debido a lo amplia de esta, nos enfocaremos en lo relacionado con el murciélago entre estas áreas culturales.

\section{Palabras clave}

Arte y mitología - El Salvador; Cerámica indígena El Salvador; Intercambio cultural - América Central; Antigüedades prehistóricas - América Central

\section{Abstract}

The Salvadorean territory is at present located in a privileged geographical area in terms of the dynamics between the Central American area and Mesoamerica which facilitates access to the Pacific Ocean; it actually is a land bridge between what North and South America are today; this is why it is crucial to determine the influence that the cultures who lived in this central part went through and to determine their print in pottery, mythology and sculpture. Given its ample spectre, we will be focusing on everything related to bats in these cultural areas.

\section{Keywords}

Art and mithologoy - El Salvador; Indigenous/Native ceramic/pottery-El Salvador; Cultural exchange - Central America; Prehistoric antiquities - Central America 


\section{Desarrollo}

El Salvador es un lugar privilegiado para comprender la dinámica regional entre las frontera fluctuante del Área Intermedia con Mesoamérica, debido a sus recursos, su geografía y la relación de su sociedad con la costa del océano Pacífico. Es por eso fundamental el estudio y la relación del actual territorio salvadoreño con el área intermedia y cuál fue su influencia, ya sea parcial o totalmente.

A continuación se presenta un estudio comparativo entre las distintas características culturales que posee el Área Intermedia, que pueden ser un reflejo de una influencia, tanto hacia el interior como al exterior del territorio salvadoreño; estas influencias se determinarán a partir de este estudio, tanto de la cerámica y estilizaciones iconográficas como de los mitos relacionados con el murciélago y otras especies que tienen que ver con el inframundo.

Los estudios sobre dinámicas culturales entre el Área Intermedia y la zona geográfica del territorio salvadoreño que corresponde a Mesoamérica son limitados, más cuando son áreas culturales que están muy cerca y forman parte del mismo corredor terrestre entre lo que ahora se conoce como Suramérica y Norteamérica, por eso es muy importante realizar estudios relacionados con la influencia entre dichas áreas y cómo esta puede ser expresada en el material cultural. Basado en esto, se tratará de responder las siguientes preguntas: ¿existe alguna relación de la cerámica entre el Área Intermedia y el actual territorio salvadoreño? y ¿existe alguna relación más profunda entre el Área Intermedia y el actual territorio salvadoreño que esté reflejada en la mitología prehispánica y en la escultura?

\section{Influencia cerámica del Área Intermedia}

La invención de la cerámica fue un avance tecnológico, tanto así que se encuentra asociada con el cambio de modo de vida de grupos cazadores recolectores o grupos sedentarios, esta nueva invención posibilitó que las personas pudieran expresar muchas representaciones estéticas sobre la cerámica (Escalona, 2009).

Teniendo esto en cuenta y realizando la comparación entre la cerámica perteneciente al Área Intermedia y la cerámica registrada en el territorio salvadoreño, podemos identificar algunas similitudes, tal y como nos plantean Braswell, Glascock, González y Fletcher (2002), quienes nos mencionan la existencia de iconografía relacionada entre las cerámicas del Área Intermedia y las identificadas en Mesoamérica, principalmente de la cerámica perteneciente al período Bagaces (Joyce, 1993, 89-90; citado por Braswell et al., 2002), ya que dichos tipos cerámicos presentan el motivo de "mono en perfil-silueta", principalmente en los tipos Chávez Blanco sobre Rojo y Tola Policromo, que son los tipos más representativos de la fase Bageces. La cerámica de Mesoamérica en la que se ha identificado dicha iconografía es del tipo Gualpopa policromo de Copán, el cual ha sido registrado en El Salvador en la zona de Chalchuapa (Sharer 1978: 51-52), así como en la de los tipos Chamelecón policromo, que pertenece al valle del Naco (Urban 1993b: 41-43; Urban y Schortman 1987: 379-381; citado por Braswell et al., 2002) y el Cancique policromo del centro de Honduras (Baudez y Becquelin 1973: 288290; Beaudry-Corbett et al., 1993: 89-90; Stone 1957: 34-36; citado por Braswell et al., 2002).

Igualmente, al realizar análisis comparativos dentro de los diferentes tipos cerámicos de El Salvador, principalmente los que aparecen en la zona oriental, y los de Nicaragua y Honduras, se logra determinar la existencia de una tradición de engobe blanco (Braswell et al., 2002). De acuerdo con Andrews (1976; citado por Braswell et al. 1994), al realizar estudios en el sitio arqueológico de Quelepa, relacionó el tipo cerámico Delirio Rojo sobre blanco con esta tradición de engobes blancos, los contextos en los que se dató dicho tipo cerámico correspondían al $750 \mathrm{~d}$. C., por lo que es la primera vez que se menciona dicha tradición en la periferia sur de Mesoamérica.

En estudios posteriores se ha determinado que en la zona de Nicaragua la cerámica con engobe blanco (principalmente el policromo Nicoya o Papagayo) pertenece al período Sapoá o a la fase Cocibolca [950-1200 d. C.] (González, Lacayo \& Niemel, 1998), por lo que esta aparición más tardía en relación con la propuesta de Andrews nos daría la pauta para inferir que la zona salvadoreña, principalmente la oriental, influenció algunas de las industrias cerámicas del Área Intermedia.

Otros tipos cerámicos que pertenecen a la tradición de los engobes blancos son: Las Vegas Policromo, del valle de Comayagua; y el Papalón Policromo, del golfo de Fonseca (Baudez 1976; citado por Braswell et al., 2002), lo cual, según el autor, puede interpretarse como un desarrollo paralelo de dicha tradición de engobe blanco. 
Smith y Heath-Smith (1980; citados por Braswell et al., 2002), mencionan que la aparición de la cerámica de engobe blanco nicaragüense refleja interacciones de esta región con zonas de México y del centro de Veracruz, durante el postclásico temprano, ya que el desarrollo de una tradición cerámica de engobe blanco en América Central, entre 750-1000 d. C., nos brinda un cambio en los diferentes desarrollos que anteriormente se dieron desde El Salvador hasta el Pacífico de Nicaragua.

Este cambio ocurrido en esta zona puede tener diferentes orígenes, algunos investigadores lo atribuyen a migraciones (e.g Andrews, 1976; Braswell et al. 1994; Day y Abel-Vidor, 1981; Healy, 1980; Lothrop, 1926; Stone, 1966), o igualmente puede deberse a la expansión o al desarrollo de más rutas de interacción (e.g., Smith y Heath-Smith, 1980), o puede ser como nos mencionan Braswell et al. (2002), que fue un proceso conjunto de ambas propuestas anteriores, por lo que no son procesos excluyentes sino incluyentes en la aparición de estas tradiciones cerámicas.

Estas influencias son mucho más profundas y continuas, lo que se ha comprendido anteriormente, pues, como menciona Lothrop (1926), incluso al examinar tipos cerámicos, como el Policromo Nicoya, se pueden apreciar formas muy similares, principalmente al hablar sobre la de la efigie de este tipo y su semejanza con algunas que presenta la cerámica Plomiza de las zonas de El Salvador y Guatemala, la cual se sabe tiene registros tempranos, desde el siglo VI d. C., por lo que se podría apreciar que influenció los estilos que luego adoptaría el Policromo Nicoya.

Pero las injerencias no se limitan simplemente a los tipos cerámicos, ya que, como indican Borgnino y Lauthelin (1994), en el sitio arqueológico Papagayo se identificaron muchos elementos pertenecientes a la cerámica Policroma Nicoya en relación con rasgos funerarios, lo cual en El Salvador también se logró apreciar con el entierro registrado en el sitio arqueológico de Loma China, donde se identificaron 34 vasijas del tipo Policromo Nicoya (ver figuras 17, 18 y 19 sobre registros en Costa Rica para comparar) en relación con un entierro (Méndez, 1983, citado por Fowler, 2011: 42-43), por lo que se podría indicar incluso que los usos culturales de la cerámica perteneciente a este grupo son muy similares en ambas zonas culturales.

Es posible encontrar evidencia del tipo Policromo Nicoya en diversos contextos arqueológicos, por ejemplo, en las investigaciones realizadas por Bernard Hermes y Juan Luis Velásquez en el Grupo 2, conocido como Palacio Pipil, del posclásico temprano, contemporáneo a Cihuatan, en el Sector 4 de esta investigación arqueológica, lograron identificar que "el material que ha permitido definir este momento proviene del Grupo 2, donde un altar y un palacio de dos recintos con un acueducto de lajas y ofrendas con clases diagnósticas como Plomizo y Nicoya Policromo fueron recuperadas [ver figura 23] (Velásquez \& Hermes, 1996, p. 557).

Además este material se relaciona con el Papagayo Policromo, aunque es probable que al momento de realizar su informe hubiesen tenido información incompleta, pero sí existe la seguridad de encontrar Policromo Nicoya en el área del sitio Cuscatlán.

Material del tipo Papagayo Policromo que es parte o equivalente del grupo-clase (?) Nicoya Policromo, que se caracteriza por la presencia de diseños en rojo, negro y naranja/crema, es evidente en fuentes trípodes con soporte efigie zoomorfa hueca, cuencos de base plana y paredes curvo convergentes con borde directo y vasos piriformes, siendo la mayor parte de la muestra de pasta de tonalidad rojiza (Velásquez \& Hermes, 1996, p. 558).

También, en el posclásico temprano, fueron encontradas figurillas Policromo Nicoya (ver figura 21), estas fueron identificadas por Zachary Revene y Karen Olsen Bruhns en el sitio arqueológico Potrero Coyol en la cordillera del Bálsamo. Los autores proponen el posclásico temprano y lo relacionan con el estilo Papagayo Pataky (Revene \& Olsen Bruhns, 2007), y tienen la misma posición e identificación que otras encontradas en costa Rica (ver figura 20).

Influencia entre el Área Intermedia y El Salvador: mitología, iconografía y escultura relacionada con el murciélago

La relación entre el Área Intermedia y Mesoamérica va más allá de redes comerciales y reflejos estilísticos en la cerámica. Al parecer hubo un vínculo más profundo entre estas culturas y se ve reflejado en su mitología, la cual puede llevar a varias preguntas sobre quién influenció a quién, o si fueron particularismos históricos en cada una de estas culturas. Si bien es cierto existe una variedad de fauna tropical que comparte esta zona geográfica, que comienza 
en el actual territorio mexicano y termina en el actual territorio colombiano, es muy probable que existan otros tipos de mitos que estén relacionados entre estas dos áreas culturales. Por el momento, la presente investigación se centrará en la mitología y las representaciones relacionadas con el murciélago, esto debido a que no existe todavía un estudio que vincule lo relacionado con este animal, pues ha sido marginado para dar prioridad a otros a los que se les da cierto romanticismo, por ejemplo, el jaguar.

\section{Mitología sobre el murciélago en Mesoamérica}

El quiróptero (Chiroptera), más conocido como murciélago, es una especie que habita en América desde antes que llegarán los Homo sapiens a esta, y que se ha logrado adaptar a distintos ecosistemas y regiones, lo cual ha hecho que existan millones; a la vez que se han beneficiado por el clima tropical, fueron parte de la fauna que cohabitó con las primeras culturas sedentarias prehispánicas. "En Mesoamérica, la fauna que cohabitaba con las sociedades prehispánicas fue diversa, y su importancia puede ser observada al contar con representaciones de esta fauna en las obras prehispánicas" (Ito, 2014, p.22).

Al convivir con estas culturas, los observaron y supieron identificar su comportamiento y sus rasgos que los hacían característicos y los diferenciaban de otros animales y de las aves. Al surgir el animismo, se le proporciono al murciélago atribuciones mágicas.

El culto al dios Murciélago en el México prehispánico se remonta al menos a 500 a. C. y sus representaciones abundan en esculturas de piedra, urnas de cerámica, pinturas, códices o topónimos. La imagen de este animal sirvió para dar nombre a poblaciones y periodos calendáricos. Debe recordarse que por oposición a las ideas de luz, cielo y vida, hay dioses del mundo subterráneo, asociados con la noche, la tierra y la muerte. En este inframundo los aztecas colocaban la morada de los desaparecidos, el Mictlan, el lugar en que reinaba Mictlantecuhtli, señor de los muertos. El murciélago, junto con la araña, el búho y el alacrán, se asociaba por lo general a la oscuridad, la tierra y la muerte (Caso en Muñoz Espinoza, 2006, p. 17-23)
Este culto al dios murciélago, del cual al parecer el registro más antiguo es del preclásico medio; y probablemente existiese algún culto más antiguo que no ha sido documentado todavía. Este culto fue apreciado por distintas etnias en Mesoamérica, y le dieron varias atribuciones y nombres, dependiendo de la región y la lengua.

Abundan las representaciones de este animal, que recibe diferentes nombres según las distintas lenguas: tzinacan, náhuatl; zotz, maya; bigidiri beela, bigidiri zinia, "mariposa de carne", zapoteco; ticuchi léhle, mixteco; thut, huasteco; nitsoasts, pame del norte; ntsúats, pame del sur; tsat's, otomí (estas últimas lenguas de la Sierra Gorda); tsoats, otomipame (Muñoz Espinoza, 2006, p. 17-23).

Obviamente la diversidad de nombres responde a la diversidad de lenguas que existían en Mesoamérica, pero independientemente de la lengua, todas estas etnias manejaban la misma mitología, la cual era clave en el núcleo duro mesoamericano, entre esta mitología tenemos el mito de Tzinacán:

Según cuenta un mito, Tzinacán nace del semen y la sangre derramados por Quetzalcóatl en uno de sus autosacrificios. Es enviado entonces a que muerda el órgano genital de la diosa Xochiquétzal, y una vez que se lo arranca, lo entrega a los dioses, quienes lo lavan, y de esa agua nacen flores olorosas. Luego lo llevan al inframundo y ahí Mictlantecuhtli, señor de los muertos, lo vuelve a lavar y de esa agua nace el cempoalxóchitl, flor de los muertos (Muñoz Espinoza, 2006, p. 17-23).

En este mito el murciélago es relacionado principalmente con su variedad como vampiro, debido a que no todos los murciélagos consumen sangre 0 animales, solo los vampiros; y relaciona la sangre y el semen como creadores de vida.

El murciélago es "el animal que despedaza y desgarra, que arranca cabezas", según Eduard Seler en su interpretación del Códice Borgia, y es uno de los "demonios" animales en que abunda el panteón mesoamericano. En el Códice vaticano B está representado con cabezas en las "manos". Los códices mayas lo muestran sosteniendo en una mano 
el cuchillo de los sacrificios, mientras que en la otra tiene a la víctima (Muñoz Espinoza, 2006, p. 17-23).

Es importante el vínculo que tiene el murciélago con los sacrificios, debido a la relación que tiene el vampiro en el medio natural con la muerte, la sangre y con la noche, el cual en el animismo prehispánico le daba atribuciones relacionadas con el inframundo, con la vida y la muerte.

El murciélago era considerado como un ser del inframundo (camazotz, "murciélago-muerte") entre los mayas quichés, asociado a la decapitación. Asimismo, en una estela de Izapa, Chiapas, aparece en el tocado de un decapitador. Por sus características, el animal llamó la atención de los antiguos mayas por ser el único mamífero cuya estructura altamente especializada le permite volar; así, lo escogieron para combinarlo con el signo de la inmolación, con lo cual se le relaciona con el sacrificio humano o al menos con una ofrenda que conlleva el concepto de derramar sangre (Muñoz Espinoza, 2006, p. 17-23).

Una de las peculiaridades que resaltan del murciélagovampiro es que es un mamífero, es decir, da de amamantar a sus crías, y además vuela pero no tiene plumas, y es un animal nocturno, lo cual hace que su vínculo con la muerte y el inframundo sea mayor, debido a que solo aparece cuando el sol se oculta; rasgos que fueron muy significativos y hacia los cuales los antiguos mesoamericanos prestaron mucha atención a la hora de asignar sus atributos mágicos. Entre las representaciones existentes del murciélago, está la de Oaxaca:

“Del periodo II de Monte Albán, se han localizado figuras de barro, con influencia maya, que representan varios dioses, entre ellos el dios Murciélago". Y señala: "Tal vez se trataba de un grupo pequeño de jefes-sacerdotes que procedían del altiplano de Chiapas o de Guatemala, pues aquí se advierten algunos rasgos semejantes. Es probable que estos elementos - premayas en cierta manera- se transformaran en objetos al estilo de Oaxaca y que hayan sido producidos localmente, no importados" (Muñoz Espinoza en Ito, 2014, p. 22).

Otras representaciones en Mesoamérica del mito del murciélago han sido encontradas en zonas cercanas al territorio salvadoreño, como es Tak'alik Ab'aj, que tiene una relación directa con los sitios arqueológicos del preclásico de Chalchuapa, específicamente Casa Blanca. "En Tak'alik $A b^{\prime}$ aj se encuentra una escultura, 'el cargador del ancestro'. Esta escultura tiene una parte de altorrelieve del murciélago en que se encuentra la nariz característica en forma de hoja con 2 volutas pequeñas (Schieber de Lavarreda y Orrego Corzo, 2010)" (Ito, 2014, p. 23).

Partiendo de esta relación mitológica del murciélagovampiro con Mesoamérica, se identificarán representaciones escultóricas de murciélagos en El Salvador.

\section{Representaciones escultóricas en El Salvador}

En el actual territorio salvadoreño se ha encontrado diversidad de esculturas e iconografías, entre estas se han identificado distintos animales, pero ha pasado desapercibido el murciélago, que ha sido identificado como un animal importante en el panteón mesoamericano y que tiene vínculos grandes con esta tradición cultural, tanto con la vida y la muerte como con los sacrificios, lo cual ha sido identificado en varias zonas y sitios arqueológicos de México, Honduras y Guatemala; y no se le ha prestado la atención debida a la hora de identificar ciertos rasgos que pudieran proporcionar otras interpretaciones en relación con la iconografía del murciélago, que comúnmente se relaciona o confunde con felinos, principalmente el jaguar, que era de los principales animales representados en la escultura mesoamericana, pero no el único. "La práctica escultórica en Mesoamérica inició durante la época de Ios olmecas. En la cultura olmeca el animal principal era el felino, pero también se encuentran varias representaciones zoomorfas, como serpiente, reptil, pájaro, mamíferos entre otros." (Ito, 2014, p. 22.)

Entre las representaciones del murciélago más cercanas a El Salvador identificadas tenemos la de Copan, las cuales tenían un vínculo directo con el San Andrés.

Para el clásico tardío (600-900 d. C.), en la ciudad de Copan se esculpieron varios altares y monumentos relacionados con los murciélagos. En este sitio los murciélagos tuvieron una fuerte carga simbólica, un ejemplo de ello es el glifo emblema que por la hoja nasal claramente muestra que corresponde a una cabeza de murciélago de la familia Phyllostomidae (ver figura 11). En 
este sitio se realizaron varias representaciones escultóricas de murciélago. En la Estructura 20, que actualmente está completamente destruida por factores naturales, se registraron varias esculturas dedicadas al murciélago que formaban parte de la decoración en la fachada del edificio (Cajas, 2009, p. 6).

Estas representaciones escultóricas estaban ubicadas en la decoración de fachadas de edificios y probablemente tenían una gran carga simbólica y ritual, pero estas representaciones no se limitan a Copan, en la zona de veracruz también se identificaron varias representaciones de murciélagos.

En varios sitios de Tabasco, Veracruz, el valle de México y otros, también se han encontrado diversas efigies de murciélagos con combinaciones antropomorfas talladas en basalto, mármol, jade, entre otros. Además de vasijas, figurillas, incensarios y urnas funerarias modeladas en barro [ver figura 12] (Cajas, 2009, p.96).

Además de estas representaciones del murciélago en estas áreas, existe una propuesta de Romero Sandoval (Romero Sandoval en Ito, 2014, p. 22), que cree "que el culto al murciélago nace simultáneamente en estas dos partes del continente (el área maya y Sudamérica), y de ahí se propaga posteriormente a otras áreas culturales, como Oaxaca, Guerrero, Veracruz y Centro de México. Tiene su apogeo en el período clásico" (Ito, 2014, p. 22), es decir, esta es la primera propuesta donde se considera que el surgimiento de la tradición mítica alrededor del murciélago, tanto en Mesoamérica como en Sudamérica (incluyendo al Área Intermedia), simultáneamente, poniendo en discusión quién influenció a quién al respecto, o si fue producto de un particularismo cultural.

El murciélago se identifica en ciertas iconografías debido a sus características morfológicas, estas peculiaridades han sido encontradas en especímenes que viven en el área mesoamericana. El biólogo Luis E. Eguiarte propone cuáles son las posibles especies que están representadas en la gráfica prehispánica, dice: "La mayor parte de las representaciones prehispánicas de murciélagos sugieren miembros de la familia Phyllostomidae (ver figuras 6 y 7), por la gran hoja nasal, una de las características más claras de ese grupo". Y añade: "Otras representaciones sugieren el complicado rostro del frugívoro
Centurio senex (ver figura 8) o el Vampyrum spectrum (ver figura 9), murciélago carnívoro que es el más grande de América. De hecho, entre las características representadas en los materiales arqueológicos se encuentran la cabeza y las garras, de las cuales nos permite identificar a este animal de manera inequívoca: el apéndice nasal (Romero S., 2013)" (Ito, 2014, p. 23).

Esta identificación por un biólogo es clave para poder comparar la iconografía o las esculturas con los animales debido a que las representaciones gráficas tenían una alta definición y eran muy detallistas. Es importante destacar que la escultura en Mesoamérica, especialmente en El Salvador, llegó a un grado de exactitud en la representación de otros seres vivos tal que es posible identificar enfermedades específicas clasificadas por la medicina moderna, las cuales obviamente pueden verse expuestas a abstracciones y estilizaciones. Tal es el caso de la figurilla estudiada por el Dr. Ramón Manuel Alemán, cirujano maxilofacial, que identificó una figurilla en la sala de religión del Museo Nacional de Antropología de El Salvador, clasificándola con una enfermedad de fisura facial de grado clínico en la escala de Tessier 3 (Alemán, 2017), esto nos ayuda a comprender el nivel de exactitud a la hora de representar a otras personas o seres vivos por parte de los escultores y artesanos prehispánicos en el actual territorio salvadoreño, es decir, si se esculpía algo con cierto detalle, abstracción o estilización, todo era intencional, nada era dejado como un error por parte de los expertos escultores prehispánicos.

Nobuyuki Ito hace la primera propuesta de una deidad murciélago expresada en escultura (ver figura 13) para El Salvador, que fue fue identificada en el sitio arqueológico El Trapiche de Chalchuapa.

De hecho, unas obras de murciélago oaxaqueñas presentan una gran hoja nasal, la cual esta estilizada en forma cuadrada alargada, mientras en Guatemala las representaciones podrían describirse como muy naturalistas. En la Cabeza de Jaguar Estilizado se encuentra una cresta nasal sobre su nariz o la nariz misma, la cual es cuadrada y alargada hacia arriba. También las volutas sobre los ojos podrían corresponder a orejas estilizadas de murciélago. Las fauces de las Cabezas de Jaguar Estilizado tienen una hendidura en la parte superior. Unas representaciones relacionadas con murciélago tienen una hendidura en la parte superior de la boca. El murciélago de Centurio 
senex tiene fauces complicadas en la parte superior, las cuales posiblemente podrían representarse con hendidura en la obra prehispánica oaxaqueña (Eguiarte, 2006). El dios oaxaqueño Pitao Cozobi tiene este tipo de la boca o fauces (López Austin, 1996). Con base en los datos antes mencionados, las fauces y la cresta podrían provenir del murciélago y la Cabeza de Jaguar Estilizado representaría un dios" (Ito, 2014, p. 23).

Basado en esta descripción de la interpretación iconográfica del murciélago y de su identificación, bien marcada en la mitología mesoamericana, es muy probable que muchas esculturas o representaciones gráficas identificadas como de jaguar en El Salvador, o para el área nuclear de las cabezas de jaguar, sean representaciones de murciélagos.

\begin{abstract}
A propósito, según R. Romero Sandoval, "pudimos encontrar la combinación de dos animales, el murciélago y el jaguar; esto se debe, en parte, a que ambos seres son de hábitos nocturnos, viven en el inframundo y tienen la facultad de ejecutar sacrificios cruentos. Al atacar a sus víctimas, las despedazan, tal como hacen los felinos con sus presas, y extraen la sangre, como lo hacen los vampiros con mamíferos". Por tal razón, es difícil definir o establecer la representación de uno de los dos indicios, jaguar o murciélago, para las esculturas conocidas como "Cabezas de Jaguar Estilizado" (Ito, 2014, pp. 23-24).
\end{abstract}

Es crucial reexaminar mucha piezas arqueológicas, tanto cerámicas como escultóricas (ver figuras 14 y 15), de las que probablemente se pueda realizar una reinterpretación por el hecho de que es muy probable que se dieran por sentadas otras interpretaciones sin haber considerado las posibilidades estilísticas y la exactitud en los detalles manejada por los escultores prehispánicos que, al ser tan exactos en su trabajo, no dejaban margen para el error. $Y$ hay que ser claros en este sentido: todo lo que esculpieron tenía un sentido para ellos y las estilizaciones fueron hechas a propósito.

En Mesoamérica, es común contar o encontrar ejemplos de combinaciones de varios animales en el arte prehispánico. Es necesario determinar cada elemento facial para una parte estilizada, comparando los ejemplares similares en
Mesoamérica detalladamente con contexto arqueológico, para poder reconocer el significado de cada elemento facial. Se debe analizar el contexto arqueológico de las Cabezas de Jaguar Estilizado para interpretar sus características plasmadas a manera de monumento escultórico (Ito, 2014, p. 24).

Es imprescindible para el quehacer arqueológico poder comparar los contextos con las piezas encontradas, aunque actualmente mucho del material cultural prehispánico que existe fue extraído de su contexto sin una investigación arqueológica formal, es por eso que la comparación iconográfica con los rasgos de especies animales que habitan la zona son muy importantes a la hora de crear interpretaciones más precisas.

En Mesoamérica se encuentran varias regiones culturales, las cuales produjeron varias obras zoomorfas. Se debe tener en cuenta las relaciones entre la diversidad de la fauna para reconocer una criatura sagrada en la cosmovisión mesoamericana. Se considera más acertado interpretar una criatura sagrada dentro del contexto cultural en la categoría de una cultura regional, a la cual pertenecen las Cabezas de Jaguar Estilizado, debido a que hay varias combinaciones de un amplio espectro de la fauna, representado en una criatura sagrada" (Ito, 2014, p. 24)

Es por eso importante relacionar distinta fauna con las representaciones estilísticas de esculturas debido a la diversidad que se manejaba en épocas prehispánicas, por lo menos en la mitología del clásico los mayas relacionaban su origen ancestral con su naturaleza ritual chamanística, como nos explica Freidel.

Freidel relaciona el parentesco divino de los mayas con su "carisma oficial", expresado en su desempeño en la realeza; en otras palabras, Freidel señala que la naturaleza chamánica del culto real entre la ideología estatal maya incluye: a) renacer después de la muerte, b) invocar dioses para que existan, c) manifestarse como deidades particulares, d) ser consortes de compañías sobrenaturales de características letales, incluyendo deidades de la guerra, e) manifestarse como eje central del cosmos, f) comunicarse con los muertos. Pero, 
¿por qué estos aspectos de ideología religiosa deberían de considerarse chamánicas? Laughton propone que el chamanismo se convirtió en una exitosa religión estatal institucionalizada, entre los mayas del clásico, con el chamán más poderoso representado como el gobernante (Traducido de Paredes, 2012, p. 44)

Habrá que analizar los contextos en los que se encontraron estas representaciones escultóricas y cerámicas para determinar si están relacionadas posiblemente con gobiernos chamánicos, pero eso entrará en otra discusión.

\section{Mitología sobre el murciélago en el Área Intermedia: cultura tairona}

El murciélago ha sido identificado como parte fundamental, tanto en la mitología antigua como moderna, para el Área Intermedia.

Aunque la mayoría pertenece a los dos siglos antes de la Conquista, existen versiones arcaicas desde el periodo nahuanje precedente (100-700 DC). El murciélago como animal se encuentra en cerámica regional del Canal del Dique (5000-3600 AC) y Malambo (1200 AC - 300 DC). Asumiendo la continuidad étnico-cultural tairona-kogui, actuales habitantes de la Sierra Nevada de Santa Marta (Colombia), la presencia de este ser anómalo es rastreada a través de mitos koguis, para quienes el murciélago, hijo incestuoso del sol, es una criatura del inframundo, estrechamente vinculada con la fertilidad y sexualidad de la mujer (Plazas, 2010, p. 159).

Esta vinculación con la fertilidad y con el inframundo es crucial para entender la importancia del murciélago en la cultura del Área Intermedia.

Según el mito, los koguis, actuales habitantes de la Sierra Nevada de Santa Marta, son "la gente del tigre". Ser jaguar, poder convertirse en jaguar, entraña en el mito la posesión del conocimiento. Un saber oculto que confiere poder sobre el entorno y la comunidad. Dentro de las cuatro tribus que sobreviven en la Sierra: koguis, ikas, wiwas y kankuamos, los mamas o sacerdotes son considerados como poseedores del conocimiento y guardianes de las culturas locales. Estos grupos hablan lenguas pertenecientes a la familia lingüística chibcha, que se extiende desde Honduras hasta el centro de Colombia. Una de ellas, el teyuan, es la lengua sagrada utilizada por los mamas para transmitir mitos, dictar normas colectivas y celebrar ceremonias de adivinación. Es una lengua antigua que, según ellos, los une a sus ancestros (Plazas, 2010, p. 161).

Es importante destacar que los mitos son compartidos por gente de habla chibcha, que está distribuida en un área mayor que los distintos grupos lingüísticos de Mesoamérica. Al inverso de Mesoamérica, la lengua es determinante para el Área Intermedia para lograr comprender la difusión de una mitología que ha logrado trascender hasta estos días con los actuales koguis.

Plazas hace una analogía entre las comunidades indígenas actuales para lograr comprender los mitos y las costumbres de las culturas prehispánicas, basándose en un hilo cultural conductor que no se ha roto en la tradición del Área Intermedia, en este caso que viene de los tairona hasta los actuales koguis. Plazas dice que está

consciente de los peligros que entraña hacer inferencias de concepciones de grupos contemporáneos para entender objetos prehispánicos, pero estoy de acuerdo con Bray cuando afirma que "estudiar a los koguis para entender el material tairona no es una analogía etnológica, sino una continuidad etnológica que los mismos indígenas reconocen como fundamental para su identidad étnica" (Plazas, 2010, p. 161)

Es por eso importante hacer esa acotación para poder comprender mejor la dinámica de esta investigación.

Plazas propone ciertos atributos al murciélago.

El murciélago, nyuíji, aparece junto al agua, el cristal de roca, ciertas aves y plantas como atributo del tuxe de los kúrcha, cuyo nombre viene etimológicamente de kulcha; semilla, concepto de fertilización, impregnación (Reichel-Dolmatoff 1985, tomo I:164-165). Aunque no puedo asegurarlo, es posible que los numerosos colgantes, cascabeles de oro y colgantes alados de piedra fueran 
utilizados, exclusivamente, por los miembros de este clan (Plazas, 2010, p. 162).

Es decir, que ciertos animales eran asignados como sus estandartes a tribus definidas.

Plazas estudia los mitos koguis para entender las tradiciones y mitología tairona, "El murciélago está presente en ocho de los 83 mitos estudiados" (Plazas, 2010, p. 163). Entre estos mitos, ella observa que hay características de los murciélagos que tienen que ser tomadas en cuenta para poder comprender la naturaleza de este animal y así comprender los atributos que los tairona pudieron haber observado en estos.

Es importante observar las características que hacen del murciélago un ser anómalo: en general, se consideran anómalos en distintas culturas, no importa su clasificación taxonómica, aquellos entes que pertenecen a varias categorías a la vez. El murciélago es un mamífero pero vuela, y además lo hace de noche y casi no ve, duerme bocabajo como si su mundo estuviera al revés; podría ser un ave nocturna pero, como mamífero, amamanta a su cría, y la protege durante largo tiempo. Su cuerpo está cubierto de pelo mientras que sus alas no. Además, es vegetariano - se alimenta de néctar de flores, insectos y frutas - y predador - chupa sangre- - Sin duda, es un animal extraño, inclusive, en la Biblia es clasificado por Moisés entre las aves prohibidas para los humanos: "Podréis comer toda clase de aves puras, más he aquí las que no comeréis: el águila [...] el pelícano [...] la cigüeña [...] el murciélago" (Plazas, 2010, p. 163-164).

Todas estas características que hacen del murciélago un animal ciertamente anómalo, comparado con los demás que existen, indudablemente fueron observadas por los antiguos taironas, pero además hay algo que tomar en cuenta, y esto es la relación entre los humanos y los animales.

La teoría antropológica del perspectivismo enunciada por Århem y profundizada por Viveiros (Århem, 1993; en Viveiros, 1998) es de gran utilidad para entender a nuestro personaje. Según él, para los amerindios "Ios animales son gente, o se ven a sí mismos como personas [...] la manifestación de cada una de las especies es un mero envoltorio (una 'vestimenta') que encubre una forma interna humana, usualmente sólo visible para los ojos de la misma especie o de algunos seres transespecíficos como los chamanes. Esta forma interna es el 'alma' o 'espíritu' del animal: [...] idéntica formalmente a la conciencia humana, materializable, podríamos decir, en un esquema corporal humano escondido detrás de una máscara animal" (Plazas, 2010, p. 164).

Esta relación humano-animal está destacada por los atributos humanizables del animal, y este está reflejado en mitos. Esta mitología tairona relaciona al murciélago con la fertilidad y la sexualidad femenina.

En este mito que explica el origen de la sexualidad y de la fertilidad femenina, la escena se da en simultaneidad. La mujer que "espanta murciélagos" es "picada" por uno de ellos. El murciélago aquí además de ser el cuidador de la sexualidad femenina es su poseedor. Es el agente activo de su fertilidad, el principio masculino necesario para crear vida. Este relato profundiza en la noción de la mujer que está acompañada por murciélagos desde su primera menstruación y los "espanta" cuando está con un hombre. El murciélago, como vampiro, se relaciona con la menstruación porque "chupa sangre". "¿Ya te picó el murciélago?", preguntan en La Sierra para indagar sobre si ya se está menstruando. Los jóvenes koguis dicen: "Ella ya es mujer. Ya le picó el murciélago" para indicar que una muchacha ya es núbil (Plazas, 2010, p. 171).

Este mito entre los kogui es fundamental para comprender el desarrollo de su sexualidad y sus expectativas procreadoras; en este entra un gran ritual relacionado con el murciélago:

La ofrenda de la primera menstruación al murciélago asegura la fertilidad futura. Al ser el murciélago-vampiro el "dueño" de la menstruación, es, a su vez, el que la administra, permitiendo que esta venga o se vaya. Es como si el murciélago fuera el "dueño" de la capacidad de procrear. Los koguis creen que los embriones se forman de semen y de sangre menstrual y por eso cesa la regla después de la concepción. Existe, entonces, una relación directa entre menstruación 
y fertilidad, menstruación y criatura. Por otro lado, para los koguis la menstruación es "sangre mala" que elimina la mujer cada mes (Reichel-Dolmatoff, 1987:86). Tal vez, en el sentido de estar inutilizada, de no servir para nada, de representar lo contrario a la vida, la muerte" (Plazas, 2010, p. 173).

Esta dualidad en la sangre menstrual es representada por la vida, la muerte, y a la vez está relacionada con el murciélagovampiro debido a que, al mismo tiempo que quita la vida con sangre, también la da plantas y árboles.

El murciélago es un importante agente fertilizador nocturno de muchas plantas tropicales, entre ellas las cactáceas. Hay algunas semillas que sólo prosperan al ser ingeridas y defecadas por él. Esta particularidad, seguramente, no pasó desapercibida para indígenas alertas a los sucesos de la naturaleza. Después de la primera menstruación y de la ofrenda, el murciélago-vampiro, o Desmodus rotundus, acompañará a la mujer para siempre. Es el símbolo de la castidad de la mujer. Él está con ella mientras esté soltera, viuda o sola, siempre que no tenga pareja. Él o ellos la rondan siempre, por eso se los puede "espantar". Parecería que juega el papel de cuidador de su sexualidad y fertilidad. Es el "dueño" de la menstruación, pero no así de la mujer (Plazas, 2010, p. 174).

En este sentido, es crucial la relación entre la mujer y el murciélago y cómo este es el guardián de su fertilidad, mas no el guardián o dueño de la mujer, solo cuida el acceso al canal de la vida, al que solo puede acceder el hombre, el cual es el único capaz de espantar al murciélago. Entre estos mitos está el de Kašindúkua, el jaguar o dios sol.

El olor de la "sangre del murciélago", menstruación de la hermana, aparece en el mito como una de las razones para que Kašindúkua cometa incesto con ella y aprenda a "comer gente". En realidad, para que abuse sexualmente de la gente. Kašindúkua, el jaguar es el símbolo de la compleja dualidad del hombre, fuente de conocimiento, pero energía desbordante que fuera de control crea el caos y causa la muerte. El papel de instigador que juega el murciélago en el mito, lo asimila al jaguar y a Heséi, la Muerte que lleva puesta una máscara de jaguar, lo vuelve cómplice del gran incitador de cometer "pecados" sexuales: incesto y homosexualidad. El origen mítico incestuoso del murciélago lo faculta para inducir a Kašindúkua al incesto, convirtiéndolo así en su promotor entre los hombres (Plazas, 2010, p. 175).

En este mito de origen, se muestra la relación inherente del jaguar y el murcielago y como estos han incidido en el equilibro del mundo.

Para los koguis, según sus mitos y rituales, el murciélago y el jaguar se relacionan en cuanto son seres del inframundo, pertenecientes a la muerte y asociados con la conducta sexual prohibida. Pero hay una diferencia entre los dos que es importante resaltar. En el caso que nos ocupa, el murciélago es quien potencializa el principio femenino, podríamos decir que lo representa, mientras que el Jaguar es el principio masculino. En este sentido, son cómplices complementarios, necesarios el uno para el otro (Plazas, 2010, p. 176).

Basados en el mito de origen de Kašindúkua, el jaguar y el murcielago son parte de la misma relación, del mismo poder dual que fertiliza el mundo y su cosmovisión, la cual está basada en la sangre, en el caso del murcielago, la sangre mala de la mujer que no tiene vida hasta que el hombre espante al murciélago y se convierta en sangre de vida,

La menstruación se identifica con el murciélago chupa sangre. La menstruación, según los koguis, es "sangre-mala" porque pertenece al murciélago, en contraste con la sangre-buena, creadora de vida, de niños, cuando la mujer se embaraza por haber estado con hombre, por haber "espantado murciélagos" (Plazas, 2010, p. 176).

La ubicación de la menstruación como elemento del inframundo concuerda con la creencia de la Tierra como La Madre primigenia cuyas cuevas, grietas y lagunas son úteros o "puertas" que permiten la entrada a sus entrañas. Esto explica además por qué la mujer menstruante es considerada peligrosa en tantas culturas; al menstruar está abierta, ligada al inframundo y con su energía "fría" puede desequilibrar al hombre y llevarlo hasta la muerte. El contacto con el inframundo y con el ámbito de los muertos asusta a los vivos (Plazas, 2010, p. 176). 
Es de suma importancia la relación que hacen los tairona y los koguis entre las cuevas, el vientre de la mujer y su cosmovisión del inframundo, debido a que las cuevasvientre, en este caso, estarían protegidas por murciélagos, por eso es crucial la relación que hacen entre estas.

\section{Representaciones escultóricas en el Área Intermedia}

Karen Olsen Bruhns (1982) propone, bajo la teoría de Richardson, que las esculturas de la baja América Central (Área Intermedia), están relacionadas con Mesoamérica, específicamente con las tradiciones escultóricas de El Salvador.

En 1940 Francis Richardson recapituló lo que era entonces conocido de estas esculturas y notó que guardaban cierta semejanza a los monumentos de piedra de la baja América Central, sugiriendo que las esculturas de América Central podrían ser debidas a intrusiones sucesivas de pueblos o ideas mexicanos dentro de América Central. Aunque ha habido, desde el estudio de Richardson, un gran incremento en la información concerniente a estas esculturas y su contexto cultural, su hipótesis preliminar ha permanecido vigente y la mayoría de las síntesis dan como un hecho que las tradiciones escultóricas de América Central son vástagos de aquellas de Mesoamérica (Olsen Bruhns, 1982) [Ver figura 25].

Entre estas representaciones del Área Intermedia, se está profundizando en la mitología kogui-tairona, debido a esto se analizarán representaciones taironas que han sido fabricadas en piedra, oro y tumbaga.

Entre el material encontrado por el pueblo tairona se encuentran distintos pendientes y pectorales hechos de oro que representan murciélagos (ver figura 15), entre otros animales, como el que se encuentra en exhibición en el Met Museum de Nueva York.

El pueblo Tairona de la Sierra Nevada de Santa Marta al norte de Colombia, produjo algunos de los más grandes y más complejos objetos de oro jamás creados en el continente americano. Este pendiente es un ejemplo excelente de la destreza y virtusidad poseída por los trabajadores de oro taironas. De considerable volumen, este muestra una figura masculina con hombreras anchas de pie en forma confrontativa con las manos en sus caderas, su cabeza es la de un cocodrilo o un murciélago. Él está usando una máscara de una animal con una cara cuadrada o dientuda y una nariz con forma adiamantada. Cubriendo su cabeza se encuentra un enorme penacho que es tan alto como la figura. Posee dos aves al frente de su gorro y piezas en los lados muy elaboradas con detalles en espiral y elementos trenzados. La figura podría ser el retrato de un gobernante, un ancestro sobrenatural, o un chamán en un estado de transformación espiritual simbólica, en la cual sus atribuciones asumen esas de un espíritu animal que proporciona ayuda. Una imagen poderosa como esta tuvo que ser utilizada por un individuo que era poderoso entre los tairona. Este pendiente fue fabricado en tumbaga, utilizando la técnica de cera perdida. Su superficie fue enriquecida por el método de reducción llamado también mise-en-couleur... [ver figura 16] [Traducido de Mitchell, 2017].

\section{Discusión}

\section{Áreas y fases culturales}

Piña Chan (Piña Chan en López Austin et al, 2008) propone, para Mesoamérica, las siguientes fases: -1) Horizonte prehistórico: del 11000 hasta el 3000 a. C. -2) Horizonte Arcaico: del 3000 al 1800 a.C. -3) Preclásico: del 1800 a. C. al 100 d. C. -4) Clásico: del 100 al 850 d. C. -5) Posclásico: del 850 al 1519 d. C., que es similar a la temporalidad utilizada por Kirchoff y modificada con más períodos.

Al comparar las fases culturales mejor fundamentadas y más aceptadas que son la de Lange (1986) para el Área Intermedia y la de Kirchoff (1960) para Mesoamérica se puede observar que el periodo prehistórico o paleoindio es similar en las dos áreas culturales, así como el periodo arcaico que llega hasta alrededor del 3000 a.C. y podemos observar en cambio una diferencia de 800 años en el desarrollo de la cerámica más temprana para Mesoamérica para el 1800 a.C. mientras que para el Área Intermedia está fechada para el año 1000 a.C. por el momento.

El equivalente al periodo clásico según Kirchoff (1960) del 100 d.C. al 850 d.C. se puede observar para la periodización de Lange (1986) Escultura de Piedra Grabada, Jade, Evolución de Sociedades de Rangos, Comunidades Formativas 
Establecidas en algunas áreas, Fuertes Cacicazgos en su mayoría en el Sur del Área Intermedia, en un periodo del 500 d. C. al 1000 d. C., el cual comienza tardíamente por 500 años al igual que Mesoamérica y termina equivalente al periodo Clásico mesoamericano alrededor del $850 \mathrm{~d}$. C. - 1000 d.C. es interesante que parece haber un quiebre regional en sus sistemas políticos con un gran alcance hasta el Área Intermedia, es probable que quizás algunas alianzas políticas o comerciales se hubiesen roto que desequilibraron la zona y por lo tanto hubo una ruptura regional que modifico la dinámica política y económica en ese momento.

La etapa equivalente al posclásico, entre el $850 \mathrm{~d}$. C. hasta la Conquista, parece que sucedieron hechos similares en el Área Intermedia en esta época en la que Lange (1986) propone que hubo "cambio y revolución, fuertes patrones de regionalización, cerámica policromada". Es interesante la dinámica regional en el Área Intermedia propuesta por Lange, en la cual se vive una serie de hechos políticos y económicos si bien es cierto similares a los de Mesoamérica, pero diferentes en forma y ejecución debido a lo distinto de los sistemas políticos de ambas regiones.

\section{Dinámica entre áreas culturales reflejadas en la distribución cerámica}

Es un hecho la distribución de la tradición policromo Nicoya para el posclásico temprano en toda Mesoamérica, principalmente en El Salvador, donde se han encontrado vasijas con estas estilizaciones similares a las de la península de Nicoya en Costa Rica (ver figuras 17, 18 y 19), en los sitios Cuscatlán (ver figuras 22 y 23), Santa María, Potrero Coyol en la cordillera del Bálsamo, Loma China y La Laguneta en el oriente de El Salvador. Es importante destacar que esta cerámica está fechada entre el clásico tardío y el posclásico temprano (900-1300 d.C.), siempre asociada con entierros y de uso ceremonial.

Además, se han hallado vínculos con el Área Intermedia en figurillas, como la encontrada en de Potrero Coyol en la cordillera del Bálsamo por Zachary Revene y Karen Olsen Bruhns, que es similar a una descubierta en Costa Rica (ver figuras 20 y 21).

\section{Mitología del murciélago en El Salvador}

La mitología entre ambas áreas es peculiarmente similar al relacionar tanto al murciélago como al jaguar con el inframundo, y hace pensar que, probablemente, o existía una relación más que comercial entre estas áreas o existía una unidad psíquica en la cual la mitología era compartida quizás con características estilísticas diferentes; y quizás con algunas diferencias relacionadas con su geografía.

En ambas mitologías el sol es relacionado con un jaguar y el murciélago con la fertilidad de la mujer. Hay autores que proponen que este culto al murciélago surge simultáneamente en ambas áreas en el preclásico, pero para el preclásico no existe evidencia documentada por lo menos para el Área Intermedia.

La escultura y representaciones del murciélago por los taironas y las representaciones en Mesoamérica son muy diferentes, pero estas en el fondo guardan un vínculo relacionado con el culto a los murciélagos que existió entre el Área Intermedia y Mesoamérica, debido a que estas fueron hechas en periodizaciones diferentes (por lo menos las que se han encontrado hasta el momento). Para los taironas en Colombia son equivalentes al posclásico mesoamericano, mientras que para EISalvador se encuentran representaciones en el preclásico y posclásico. La cronología de estos restos materiales induciría a pensar que Mesoamérica influenció al Área Intermedia en dicho culto, pero no existen estudios concluyentes que nos guíen a esta conclusión.

Influencia y relación de mitos sobre el murciélago en el preclásico

Para el preclásico, Nobuyuki Ito documenta una representación de murciélago en el sitio El Trapiche (ver figura 13) basado en su teoría, la cual es muy válida para esta área cultural relacionada con otros hallazgos en México y Guatemala para esta época, es probable que existan otras representaciones de murciélagos que se han identificado como jaguares. Entre esta clasificación es posible analizar otras, propuestas como la de las Cabezas de Jaguar Estilizadas hecha por Federico Paredes, en cuya clasificación identifica a todas como jaguares, cuando la morfología de algunas aparenta la de un murciélago, al analizarlas bien (ver figuras 14 y 15 ).

Influencia y relación de mitos en sobre el murciélago en el clásico

En El Salvador, en el sitio Joya de Cerén probablemente la Estructura 12 pudo haber estado asociada con rituales de 
fertilidad como los que practicaban los taironas, debido a que, al igual que estos, se tenía un área especial destinada a la adivinación; en este lugar se encontraron

\section{cuencos hemisféricos policroma copador} (asociado con la esfera y cultura maya de Copán y El Salvador, garantizando un vínculo étnico y por lo tanto que comparte la misma mitología, dado que en Copan existe iconografía relacionada a los murciélagos (ver figura 11) lo cual podría dar a entender que existía una tradición regional) con decoración externa Melon Stripe, y decoración interna zoomorfa. La estructura está construida sobre un nivel alto en relación con el resto de las estructuras y su arquitectura es un sistema de plataformas y subplataformas, presenta elementos decorativos en las paredes pintadas en colores blanco y rojo, así como el uso de celosías y huecos en las paredes (Alfaro Moisa, 2013, pp. 73-744).

Dentro de los hallazgos figuran artefactos como fragmentos de figurillas, anillo doble, malacates, vasijas no utilitarias, vasijas con resto de pintura roja, vasijas tipo Guazapa Mititlan, manos de metate, navajas prismáticas de obsidiana, fibras, morros pintados, bivalvos (normalmente relacionados a los sacrificios con sangre y la femineidad), cenizas de madera, minerales, astas de venado y dos pequeños promontorios de frijoles (Alfaro Moisa, 2013, p. 74).

El venado simboliza la fertilidad de la naturaleza, según Linda Brown (Cobos \& Sheets, 1997, pp.89-90). Brown también menciona que todos los artefactos encontrados en la Estructura 12 están relacionados con el uso femenino, por lo que es posible suponer que el curandero haya sido una mujer que atendía a los enfermos. Partiendo de esta teoría, hay que indagar más a fondo, basados en la cosmovisión maya sobre la fertilidad y las mujeres, si existían rituales asociados con las deidades murciélago en este lugar, las cuales estaban relacionadas con la sangre de la menstruación; y en el área tairona, con "penetraciones rituales" asistidas por la chamana y un familiar de la persona y la bienvenida a la vida sexual del joven varón por parte de la chamana, como se acostumbra con una cosmovisión similar en la cultura tairona.

\section{Método}

La metodología utilizada fue una investigación documental, en la cual se consultaron distintas fuentes, revistas y libros, tanto de publicación sobre Mesoamérica, el Área Intermedia como específicamente de El Salvador. Estos documentos tenían que aportar información sobre cerámica, mitología e iconografía escultórica que tuvieran alguna relación diacrónica (que una suceda o influencie a la otra) o sincrónica (que sucedan al mismo tiempo) entre ambas áreas culturales, lo cual ayudaría a crear una discusión sobre si el material cultural representa algún vínculo solido entre áreas culturales.

\section{Conclusiones}

\section{Influencia del Área Intermedia en la cerámica}

Finalmente, se puede concluir que con base en los diferentes estudios realizados, tanto en el área mesoamericana como en el Área Intermedia, ha existido una relación muy cercana entre dichas zonas, tanto así que afectó incluso elementos tan comunes como es la cerámica.

Las influencias en la cerámica se dieron principalmente durante el clásico tardío y el postclásico temprano (González, Lacayo \& Niemel, 1998; Andrews, 1976), teniendo su origen como tradición de engobes blancos en la zona oriente de El Salvador, para posteriormente ser trasladada y adoptada por otros grupos del Área Intermedia, tanto así que incluso algunos grupos cerámicos no solo adoptadoron la característica del engobe, sino que también se han visto influenciados por las formas (Lothrop, 1926) y por la iconografía, en otros casos (Joyce, 1993, pp. 89-90; citado por Braswell et al., 2002).

Posteriormente, estos tipos cerámicos producidos bajo influencia mesoamericana en el Área Intermedia se identifican en El Salvador por la acción tanto de comercio y de migraciones en ambas direcciones (Braswell et al., 2002). Tal es el caso del tipo cerámico policromo Nicoya, el cual es producido en Nicaragua, eso se puede asegurar debido a cómo Borgnino y Lauthelin (1994) nos indican que dicho tipo cerámico se puede identificar en zonas como Guanacaste con la siguiente afirmación: "Se encuentra por doquier en Guanacaste", indicacando que la densidad de producción y 
utilización de esta cerámica era muy alta en esta zona, en comparación con otras zonas de Centroamérica donde su porcentaje es más bajo o nulo.

Igualmente, Bishop (1994) realizó estudios de la composición química de las pastas de diferentes tiestos de este tipo cerámico que procedían de varios sitios arqueológicos, llegando a la conclusión de que las arcillas que químicamente tienen similitud con las que se produjeron dichos elementos cerámicos pertenecen a la zona de Rivas, Nicaragua, por lo que no sería extraño que los elementos cerámicos identificados en El Salvador, que pertenecen a este grupo, provengan de la misma zona.

Dando como resultado una influencia continua en ambas direcciones en muchos elementos culturales, entre estos la cerámica.

\section{Mitología y escultura relacionada con el murciélago}

Podemos concluir en relación a esto que definitivamente existe una influencia entre estas áreas culturales debido a las similitudes propuestas para el culto al murciélago y el jaguar los cuales son animales que representan una dualidad, debido a que el jaguar representa la fuerza masculina y el murciélago el guardián de la fertilidad femenina para ambas zonas, lo cual hace probable que además de la mitología algunos ritos que se practicasen en estas áreas estuvieran relacionados o fueran los mismos.

El estilo escultórico es totalmente diferente, para los taironas está fechado en el posclásico y está fabricado en tumbaga, mientras que para las regiones de Costa Rica y Tierradentro en Colombia se encuentran decapitadores tallados en piedra para el equivalente a Mesoamérica entre el clásico y posclásico, estos decapitadores son un atributo al dios murciélago, probablemente lo sean pero lo seguro es que no existe un vínculo estilístico en la iconografía del murciélago por lo menos en los hallazgos hasta el momento.

\section{Referencias}

Amaroli, Paul (1986). En la Búsqueda de Cuscatlán, Un Proyecto Etnohistórico y Arqueológico. Patronato Pro-Patrimonio Cultural, Banco Cuscatlán, San Salvador, El Salvador.

Amador, Fabio Esteban (2011). La Laguneta, sitio arqueológico de oriente: un estudio del paisaje cultural, La universidad, pp. 185-206.

Alfaro Moisa, Ana Claudia María (2013). "Análisis de la Cerámica Copador Procedente de Cuatro Sitios Arqueológicos de la Fase Payu del Occidente y Centro de El Salvador: Tazumal, Joya de Cerén, San Andrés y Madre Selva". Trabajo de Graduación, Universidad Tecnológica de El Salvador.

Alemán, Ramón Manuel (2017). “Fisura Facial, Tessier 3 en figurilla Antropomórfica en El Salvador", The CleftPalate Craniofacial Journal, American Cleft PalateCraniofacial Association.

Barfield, Thomas J. (1997). Diccionario de Antropología. Editorial: Siglo XXI Editores, México, D.F., 2000. ISBN 10: 9682322383 / ISBN 13: 9789682322389.

Brown, Nina (2001). "Friedrich Ratzel, Clark Wissler, and Carl Sauer: Culture Área Research and Mapping". University of California, Santa Bárbara, CA.

Carmack, Robert (1993). Historia General de Centroamérica. San José, Costa Rica: Flacso.

Cajas, Antoni (2009). Los Murciélagos en el Arte Maya, revista Asociación FLAAR Mesoamérica, Junio de 2009.

Cobos, Rafael (1994). Arqueología. Síntesis de la Arqueología de El Salvador, 1850-1991. Colección Antropológica e Historia, pág. 22.

Cobos, Rafael \& Sheets, Payson (1997). San Andrés y Joya de Cerén, Patrimonio de la Humanidad, Bancasa.

Díaz Couder, Ernesto (1998). Diversidad Cultural y Educación en Iberoamérica, Revista Iberoamericana de Educación, n. ${ }^{\circ}$ 17, Mayo -Agosto 1998, OEI, Organización de Estados Iberoamericanos.

Fowler, William (2011). El complejo Guazapa en El Salvador: La diáspora tolteca y las migraciones pipiles. La universidad, pp. 17-66. 
Geurds, Alexander (2015). Cronología Prehispánica en Centroamérica: un Acercamiento Preliminar, de Leiden y Universidad de Colorado Boulder, En revista Mi Museo y Vos, Año 9, n. ${ }^{\circ} 31$, Granada, Nicaragua.

Herskovits, M. (1924). A preliminary consideration of the culture areas of Africa. American Anthropologist, pp. 50-63.

Hurtado de Mendoza, Luis \& Troyo Vargas, Elena (2007). "Simbología de Poder en Guayabo de Turrialba", Cuadernos de Antropología 2007-2008.

Ito, Nobuyuki (2014). Informe Final del Proyecto “Investigación Arqueológica a Través de Sondeo Geofísico en el Área del Trapiche, Chalchuapa (2012-2014), Proyecto Arqueológico El Salvador, Universidad de Nagoya.

Jaramillo Arango, Antonio (2015). “Culturas y pueblos precolombinos de la costa pacífica. Navegación e intercambio entre los Andes centrales, el Área Intermedia y Mesoamérica", p. 291-316, Universidad Nacional Autónoma de México, Instituto de Investigaciones Históricas/Instituto Nacional de Antropología e Historia.

Kirchhoff, Paul (1960). Mesoamérica, sus límites geográficos, composición étnica y caracteres culturales. Tlatoani.

Lange, Frederick (1986). "Central America and the Southwest: A Comparison of Mesoamerica's Two Peripheries. Research and Reflections" in Archaeology and History: Essays in Honor of Doris Stone, coordinado por E. Wyllys Andrews V., pp. 159-177.

Levinson, David (1994). Encyclopedia of World Cultures, Vol. 1, North America, G.K. Hall \& Co.

López-Austin, Alfredo \& López Lujan, Leonardo (1992). El Pasado Indígena, El Colegio de México, México D F., 2001.

López-Austin, Alfredo \& López Lujan, Leonardo (2008) La Periodización de la Historia Mesoamericana, Tiempo Mesoamericano I, Arqueología Mexicana.
Méndez, M. (1983). Proyecto de rescate arqueológico Embalse San Lorenzo. San Salvador: Informe inédito, Departamento de Arqueología, Secretaría de Cultura. Mitchell, Jan (2017). Gold Masked Figure Pendant, Tairona Culture, Met Museum http://www.metmuseum.org/ toah/works-of-art/1991.419.31/

Muñoz Espinosa, María Teresa (2006). “El culto al dios Murciélago en Mesoamérica", en Arqueología mexicana, ISSN 0188-8218, Vol. 14, n. 80 (JulioAgosto) pp. 17-23.

Paredes Umaña, Federico A. (2012). “Local Symbols and Regional Dynamics: The Jaguar Head Core Zone in Southeastern Mesoamerica During the Late Preclassic, A Dissertarion in Anthropology Presented to the Faculties of the University of Pennsylvania in Partial Fulfillment of the Requirements for the Degree of Doctor of Philosophy".

Plazas, Clemencia (2010). “¿Nurlita, el Humano-Murciélago Kogui, Heredero del Icono Tairona?", en revista Arqueología del Área Intermedia, n. ${ }^{\circ}$ 8, 2010.

Revene, Zachary \& Olsen Bruhns, Karen (2007). Nicoya Polychrome Statuette Found in El Salvador, pp. 102-103.

Rovira Morgado, Rossend (2001). "Mesoamérica: Concepto y Realidad de un Espacio Cultural", Doctorando en el Departamento de Historia de América II, Universidad Complutense de Madrid.

Sabloff \& Fash ().2000 Gordon Willey in the Americas.

Velásquez, Juan Luis y Bernard, Hermes (1996). “El proceso evolutivo del centro de El Salvador: Su secuencia de ocupación y relaciones". En IX Simposio de Investigaciones Arqueológicas en Guatemala, 1995 (editado por J.P. Laporte y H. Escobedo), pp. 554583. Museo Nacional de Arqueología y Etnología, Guatemala (versión digital). 
Figura 1. Las divisiones culturales de América según Kroeber (López Austin, p. 60)

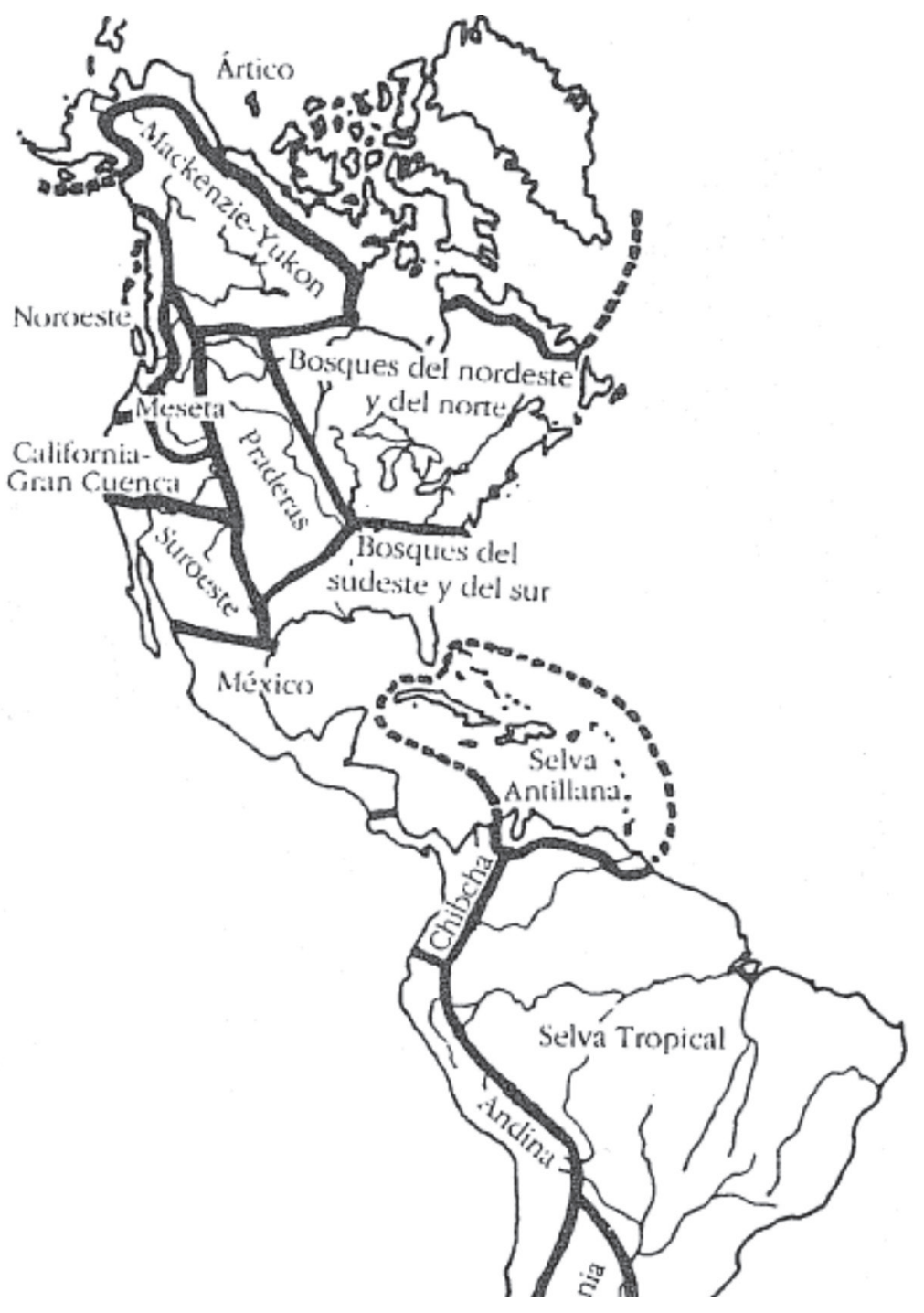


Figura 2. Las divisiones culturales de Norteamérica (Levinson, 1994, p. 25)

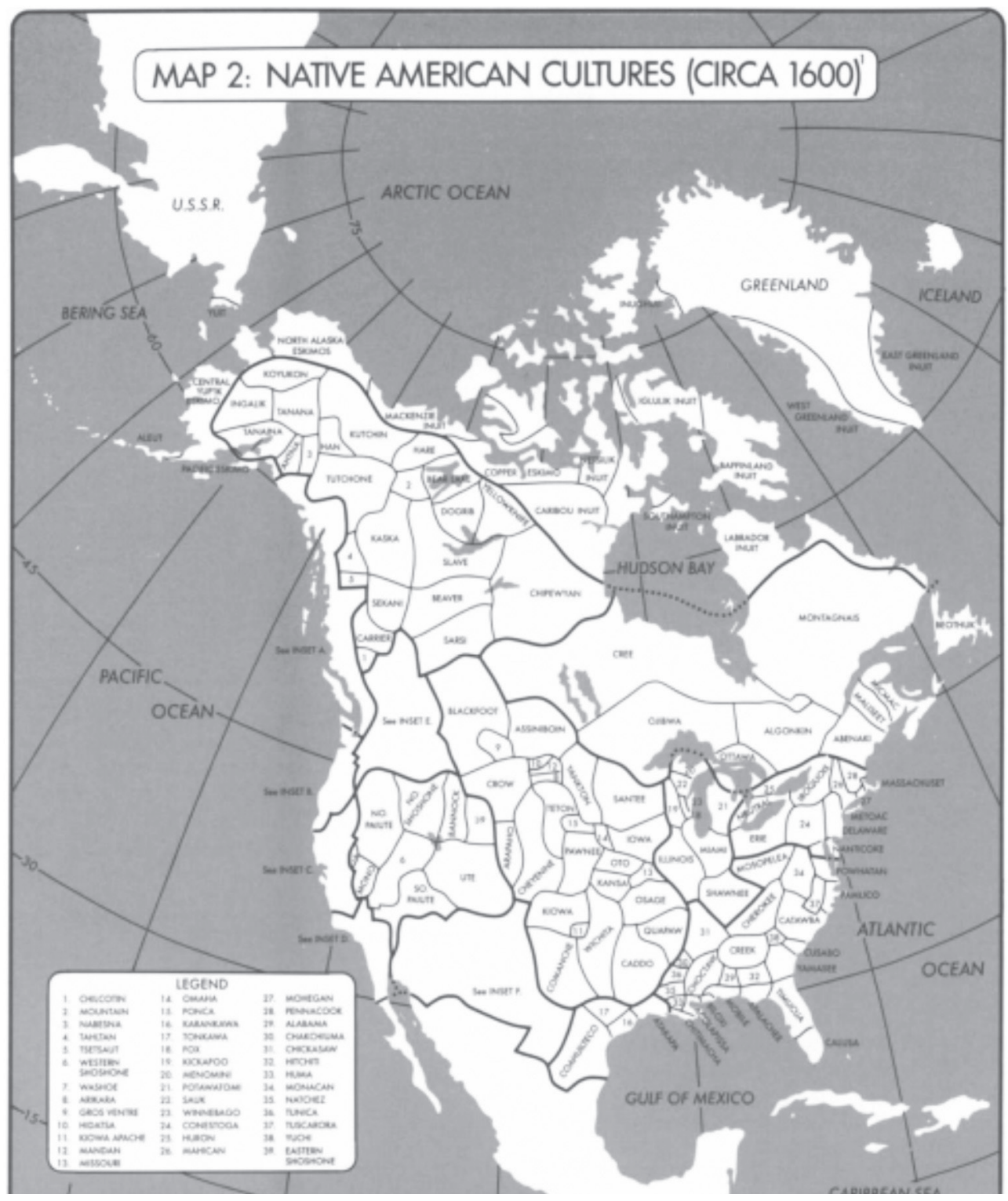


Figura 3. Las divisiones culturales de Mesoamérica (López Austin, p. 65)

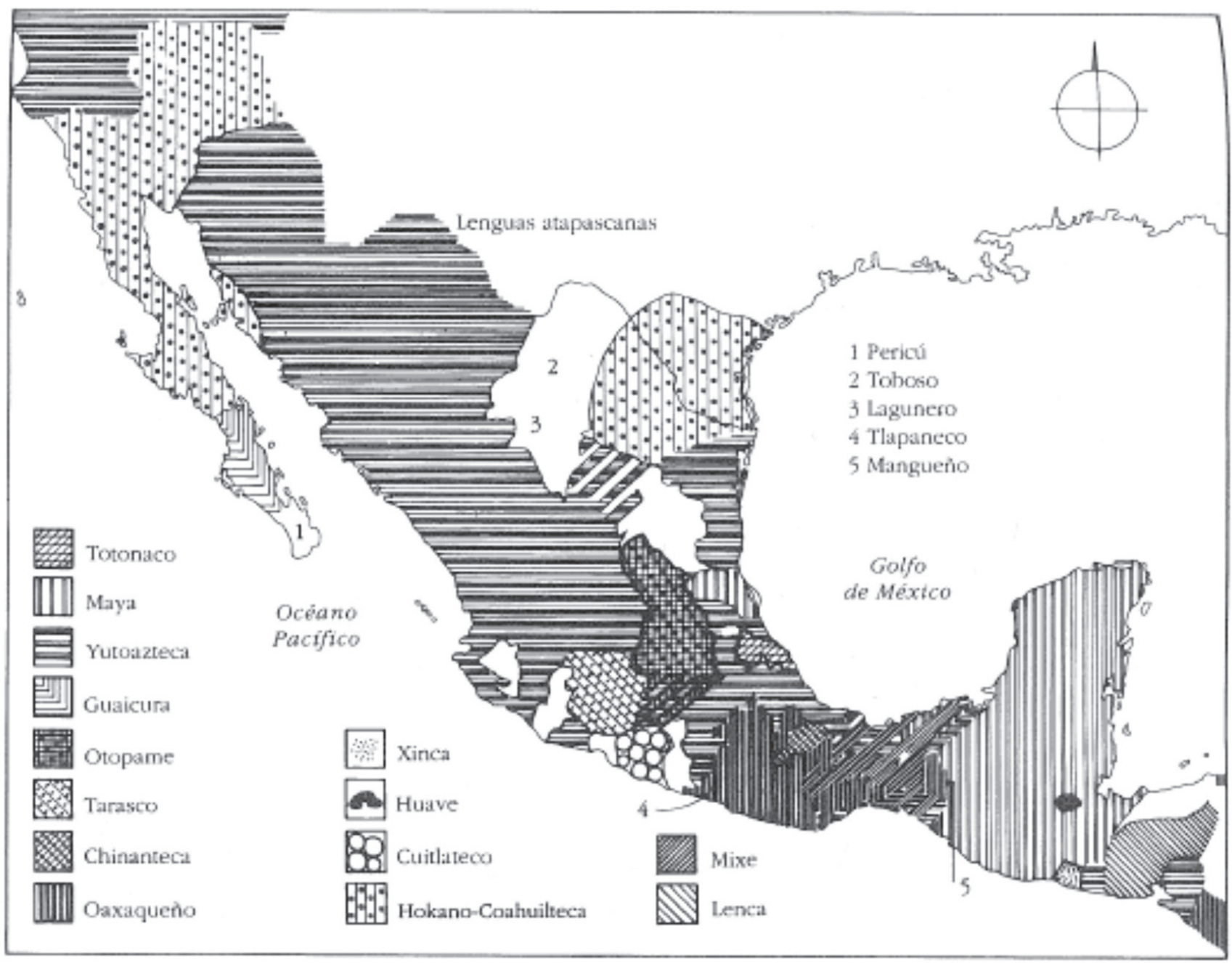


Figura 4. Las divisiones culturales de Suramérica (Díaz Couder, 1998)

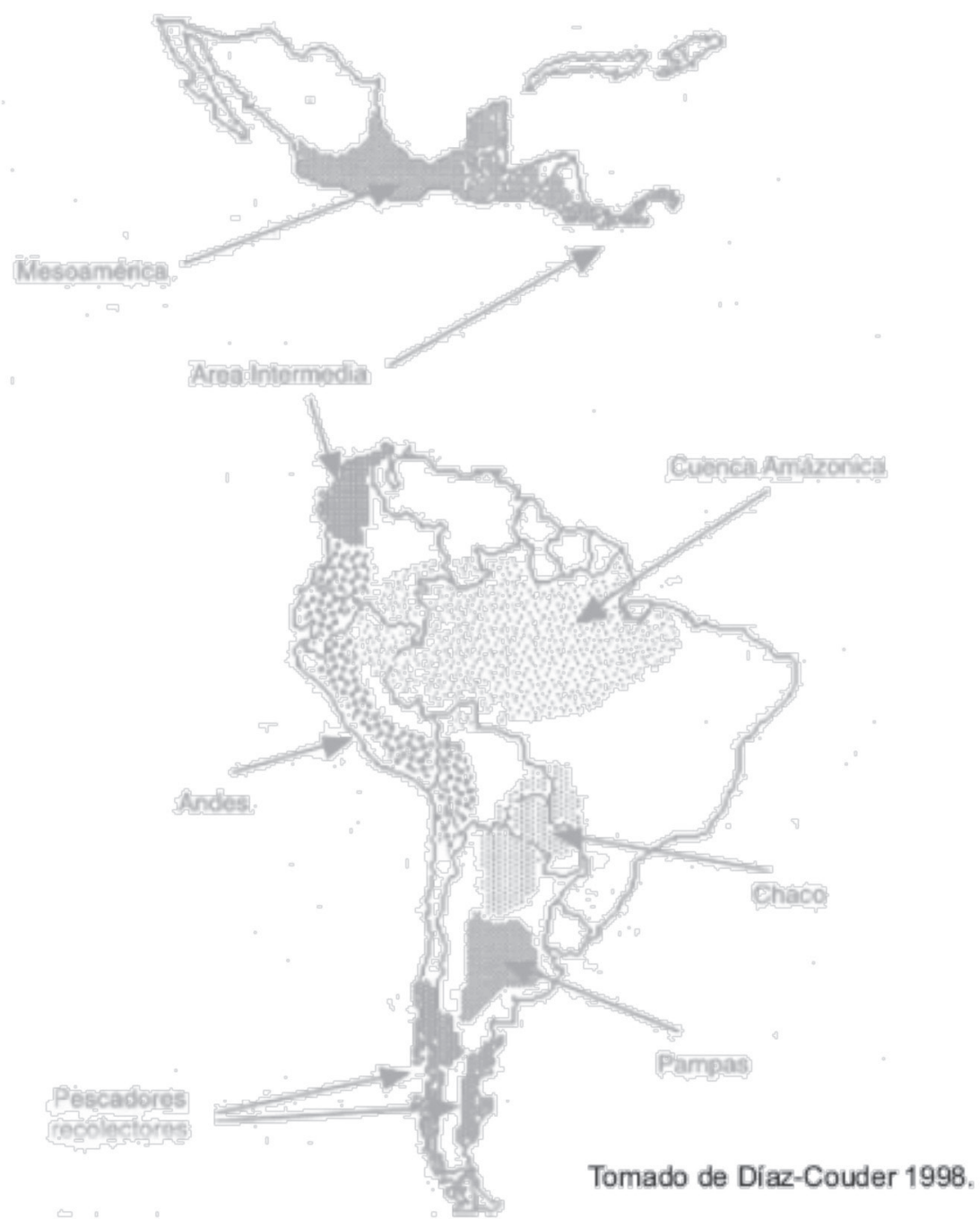


Figura 5. Periodización de Mesoamérica (López Austin et al, 2008)

\begin{tabular}{|c|c|c|}
\hline $\begin{array}{c}\text { PERIODO } \\
\text { CRONOLÓGICO }\end{array}$ & $\begin{array}{c}\text { CULTURAS } \\
\text { MESOAMERICANAS } \\
\text { MÁS } \\
\text { IMPORTANTES }\end{array}$ & $\begin{array}{l}\text { CARACTERISTICAS } \\
\text { SOCIOCULTURALES }\end{array}$ \\
\hline $\begin{array}{l}\text { HORIZONTE } \\
\text { PRECLÁSICO } \\
\text { (1500 a.C. - } 100 \\
\text { d.C.) }\end{array}$ & $\begin{array}{c}\text { Cultura Olmeca } \\
\text { (Costa del Golfo, } \\
1200 \text { - } 500 \text { a.C.) } \\
\text { Cultura de San José } \\
\text { Mogote (Oaxaca, } \\
800-500 \text { a.C.) } \\
\text { Cultura de Izapa } \\
\text { (Guatemala, } 300 \text { - } \\
100 \text { a.C.) Cultura de } \\
\text { El Mirador } \\
\text { (Guatemala, c. } 400 \\
\text { a.C.) }\end{array}$ & $\begin{array}{l}\text { Concentración de la } \\
\text { población en centros } \\
\text { ceremoriales. } \\
\text { Aceleración de los } \\
\text { procesos de } \\
\text { complejidad } \\
\text { ocupacional y } \\
\text { sociopolitica. Inicio de } \\
\text { rutas de intercambio a } \\
\text { larga distancia. } \\
\text { Influencia de la } \\
\text { cultura olmeca. } \\
\text { Proceso de } \\
\text { urbanización } \\
\text { incipiente }\end{array}$ \\
\hline $\begin{array}{l}\text { HORIZONTE } \\
\text { CLÁSICO (100 } \\
\text { d.C. }-950 \text { d.C.) }\end{array}$ & $\begin{array}{c}\text { Cultura de } \\
\text { Teotihuacan (Valle } \\
\text { de México, } 100 \text { - } 650 \\
\text { d.C.). Cultura de } \\
\text { Monte Albán (10 d.C } \\
0 \text { - } 950 \text { d.C.). Tikal - } \\
\text { Copán -Palenque } \\
\text { (Área Maya, } 200 \text { - } \\
900 \text { d.C.). Cholula - } \\
\text { Cacaxtla - } \\
\text { Teotenango - } \\
\text { Cantona (Centro de } \\
\text { México, } 650 \text { d.C - } \\
950 \text { d.C.). El Taiin } \\
\text { (Costa del Golfo, } 650 \\
\text { d.C.-950 d.C.) }\end{array}$ & $\begin{array}{c}\text { Vida urbana } \\
\text { temprana. } \\
\text { Estratificación social } \\
\text { en función del oficio u } \\
\text { la ocupación. } \\
\text { Profunda relación } \\
\text { entre las elites } \\
\text { mesoamericanas. } \\
\text { Influencia de la } \\
\text { cultura teotihuacana. } \\
\text { Auge de la cultura } \\
\text { maya. Inicio de un } \\
\text { proceso de } \\
\text { militarización en la } \\
\text { esfera sociopolitica. }\end{array}$ \\
\hline $\begin{array}{l}\text { HORIZONTE } \\
\text { POSTCLÁSICO } \\
\text { (950 d.C. - } \\
1519 \text { d.C.) }\end{array}$ & $\begin{array}{c}\text { Cultura Tolteca } \\
\text { (Centro de México, } \\
950 \text { d.C. - } 1250 \text { d.C. } \\
\text { ). Señorios Mixtecas } \\
\text { (Oaxaca, } 1250 \text { d.C. - } \\
1519 \text { d.C.). Chichén } \\
\text { Itzá - Mayapán - } \\
\text { Uxmal (Área Maya, } \\
950 \text { - } 1450 \text { ). Reino } \\
\text { Tarasco (Occidente } \\
\text { de México, } 1300 \text { d.C. } \\
\text { - } 1519 \text { d.C.). Imperio } \\
\text { Mexica.Tenohos }\end{array}$ & $\begin{array}{l}\text { Vida urbana compleja. } \\
\text { Intensa actividad } \\
\text { comercial. } \\
\text { Fragmentación } \\
\text { sociopolitica. } \\
\text { Expansión de redes } \\
\text { de influencia } \\
\text { intelectual e } \\
\text { ideológica en } \\
\text { Mesoamérica. Tributo } \\
\text { Menmotimiontn militar }\end{array}$ \\
\hline
\end{tabular}


Figura 6. Murciélago Phyllostomidae (López Austin et al, 2008)

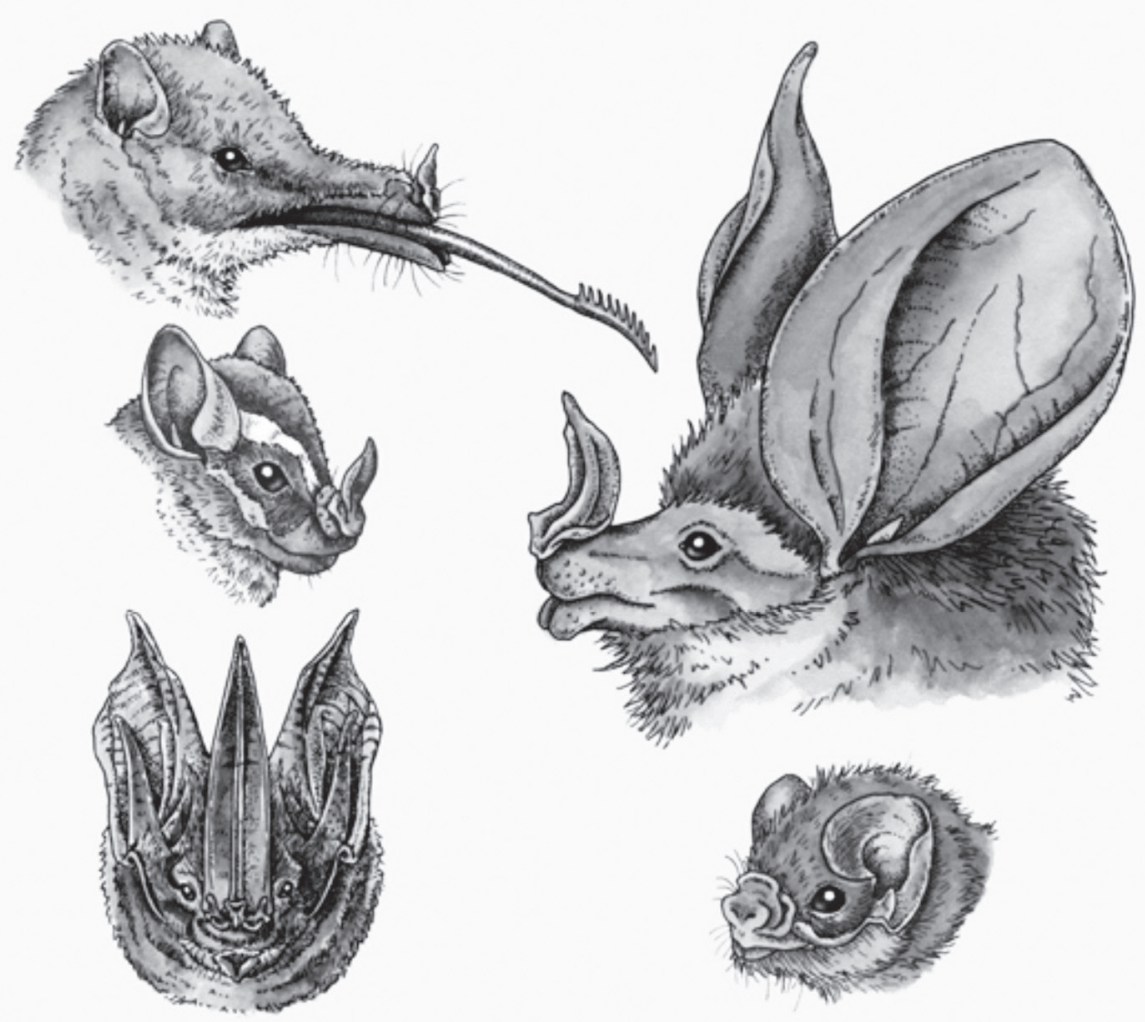

Figura 7. Clasificación, murciélago familia Phyllostomidae (López Austin et al, 2008)

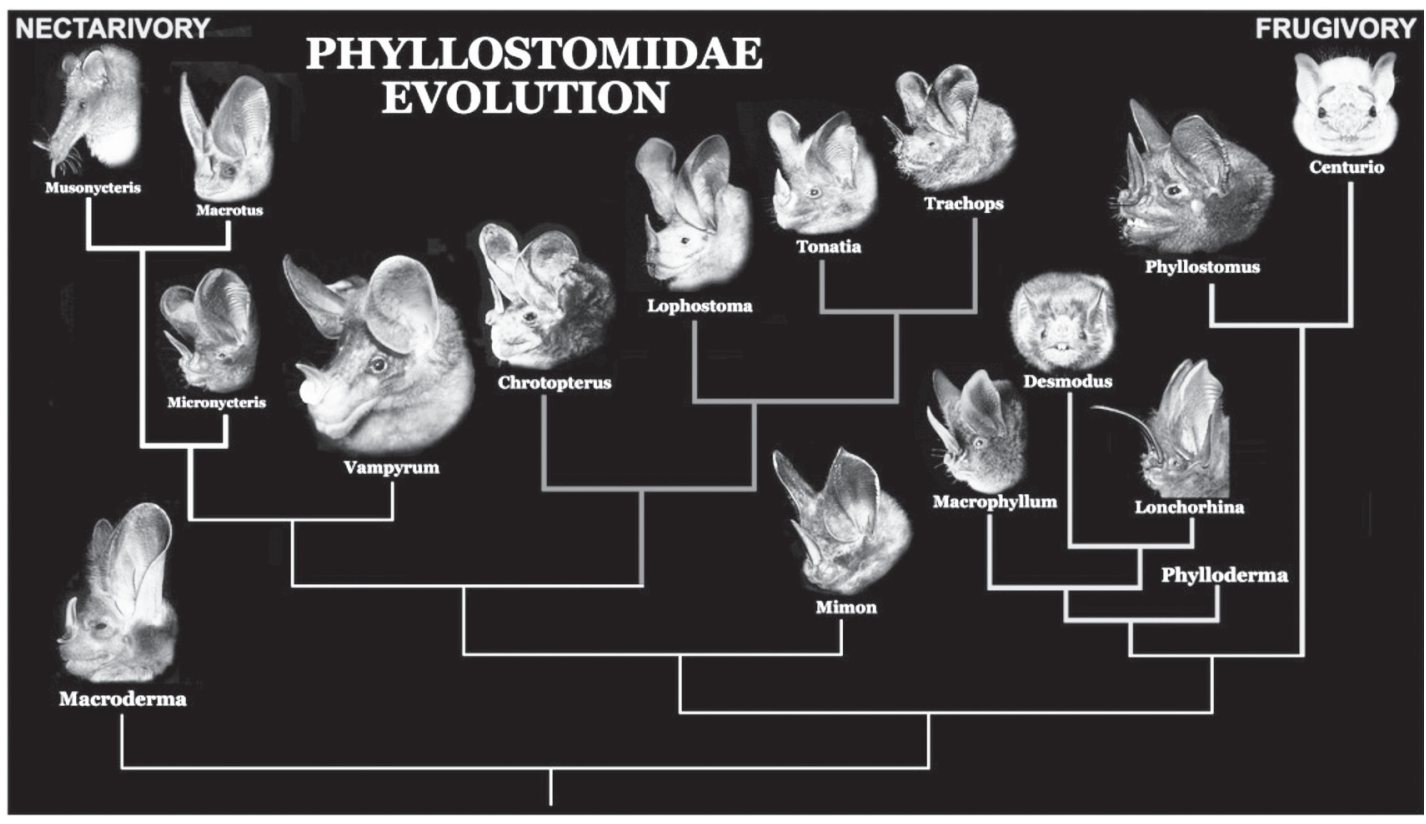


Figura 8. Murciélago Centurio cenex (López Austin et al, 2008)

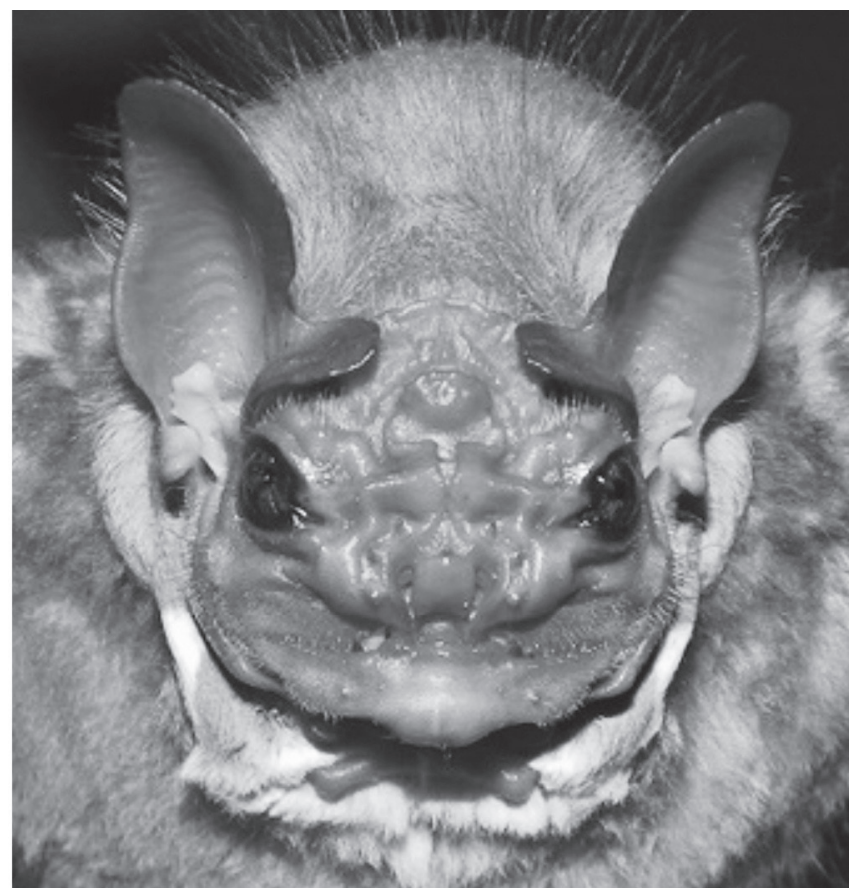

Figura 9. Vampyrum spectrum (López Austin et al, 2008)

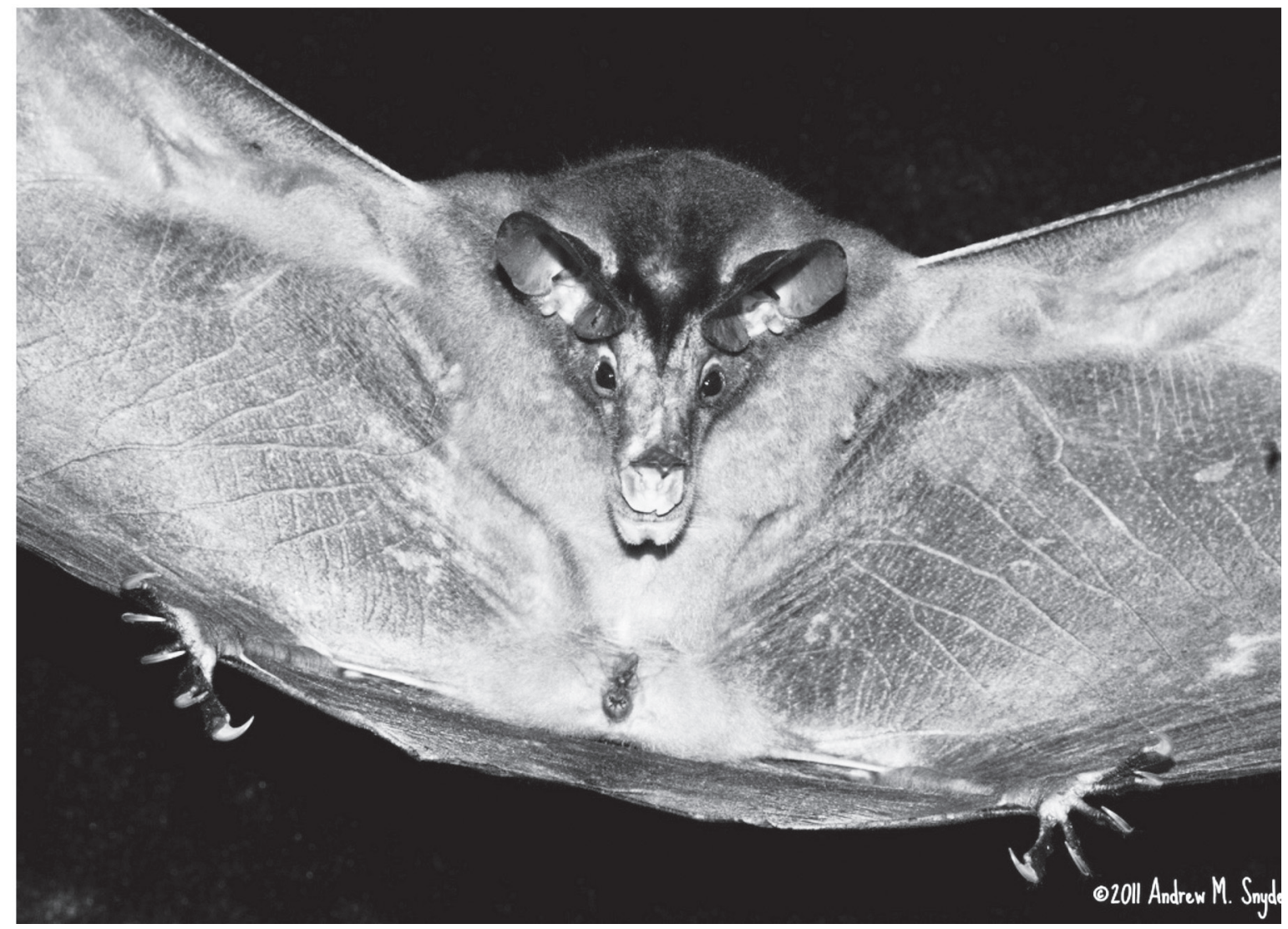


Figura 10. Ubicación Vampyrum spectrum en América (López Austin et al, 2008)

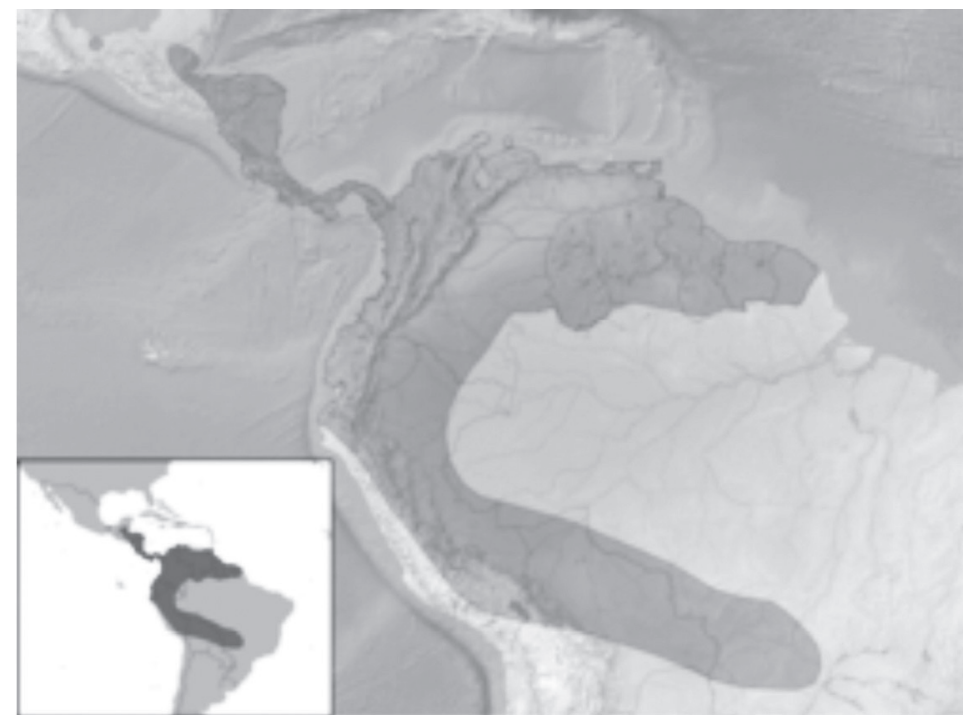

Figura 11. Escultura de murciélago encontrada en Copán, Honduras

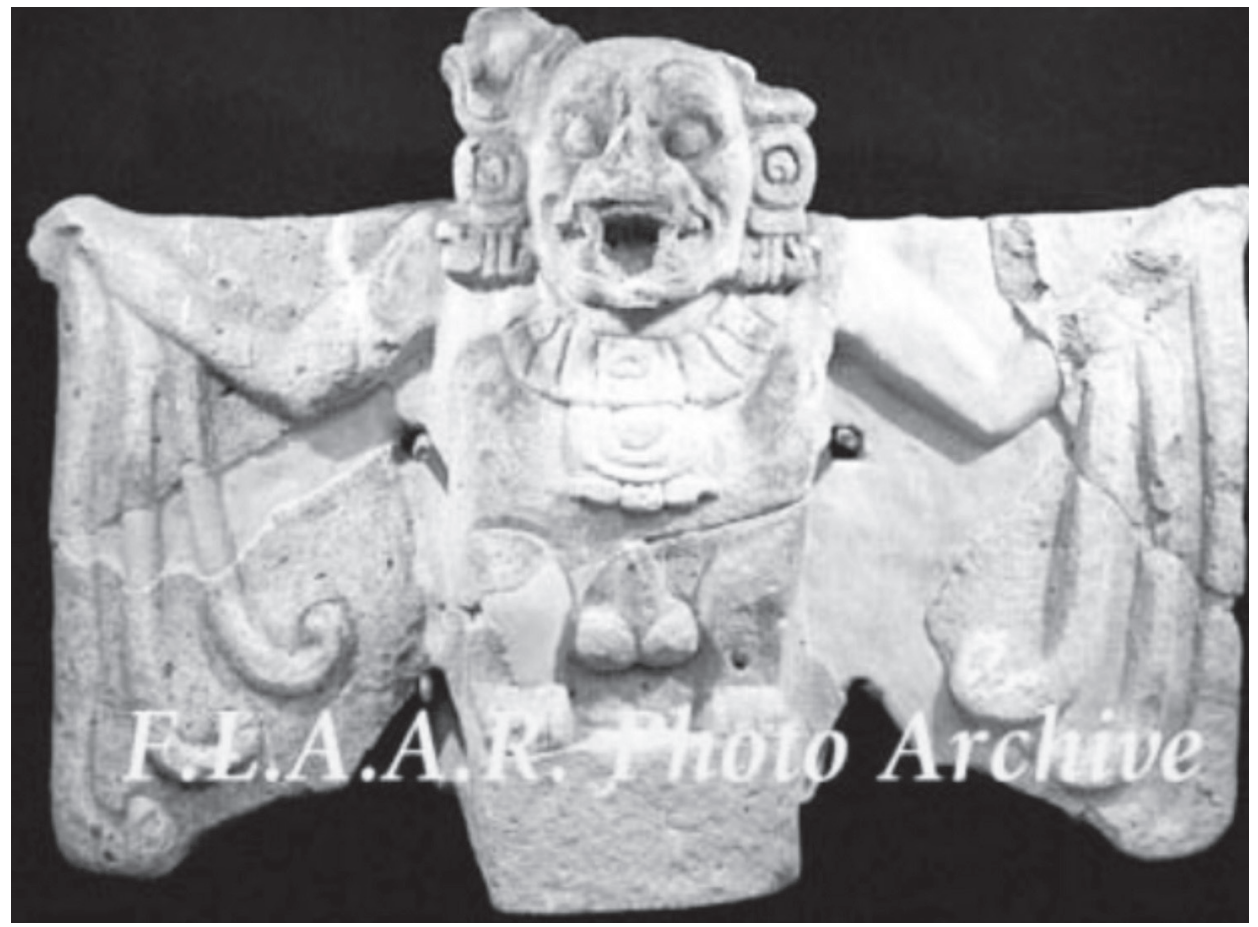


Figura 12. Vasija con repeticiones de cabezas de murciélago en relieve, Tabasco, Veracruz
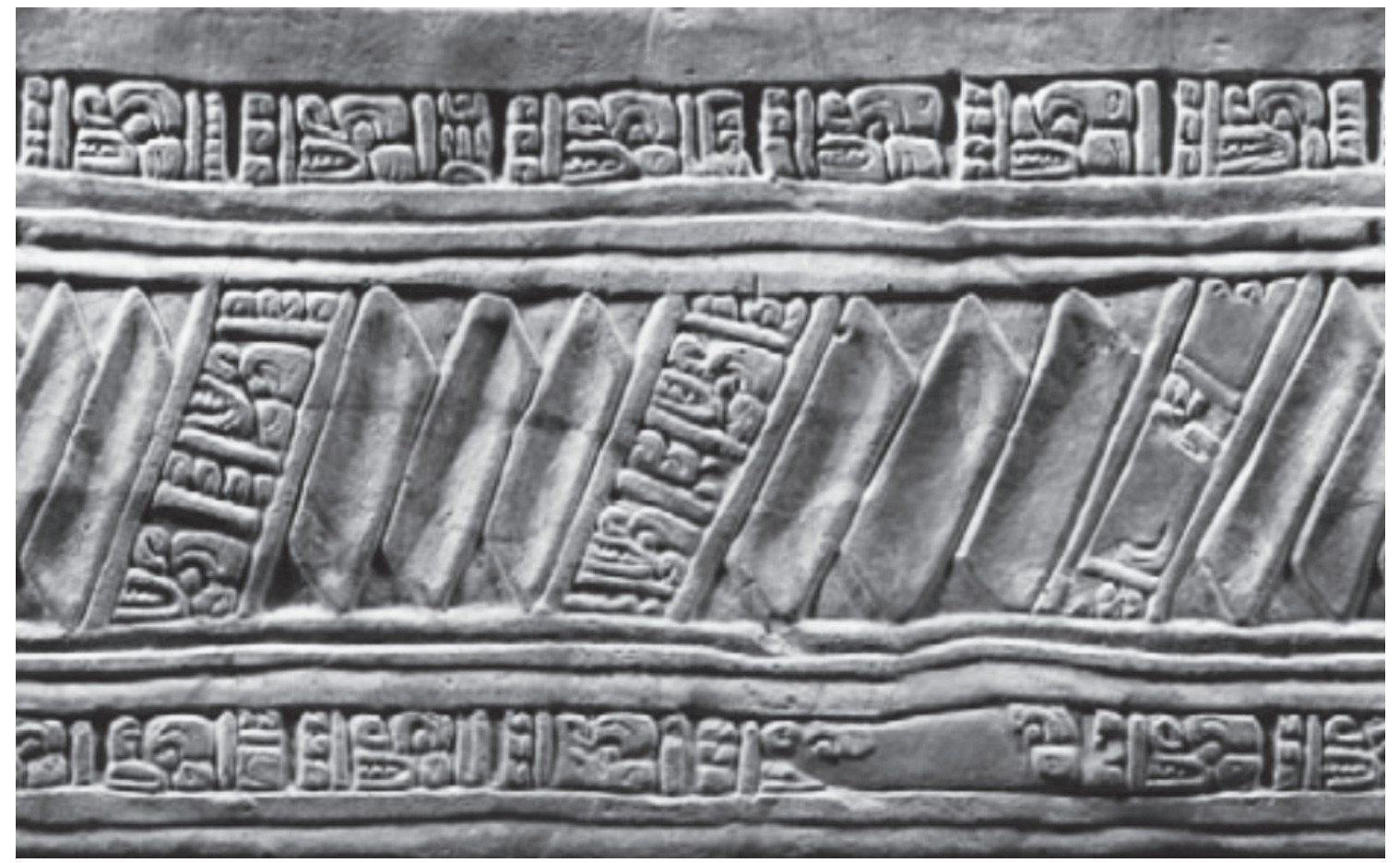

Figura 13. Cabeza de jaguar estilizada identificada como murciélago, sitio El Trapiche, El Salvador (Ito, 2014)

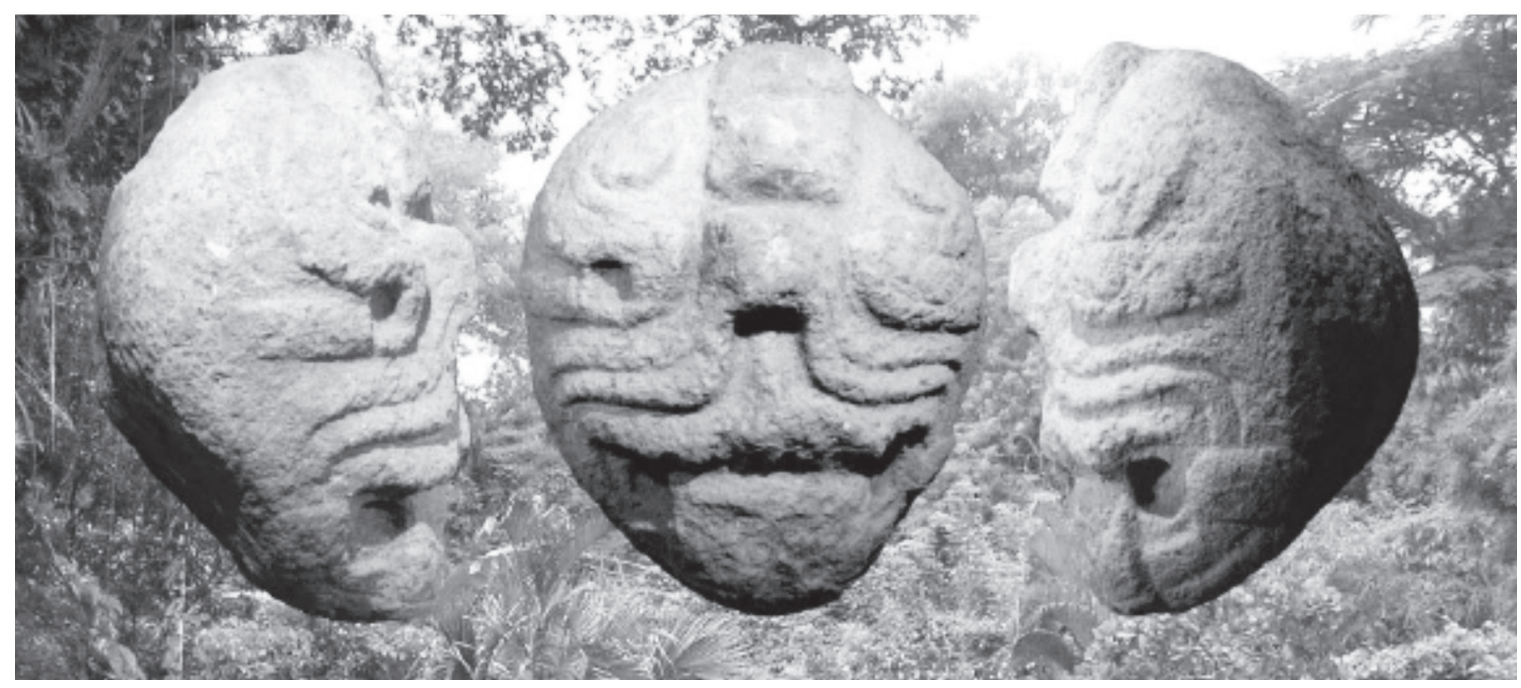


Figura 14. Cabeza de jaguar estilizada, probablemente murciélago, M24, El Salvador (Paredes, 2012, p. 103z)

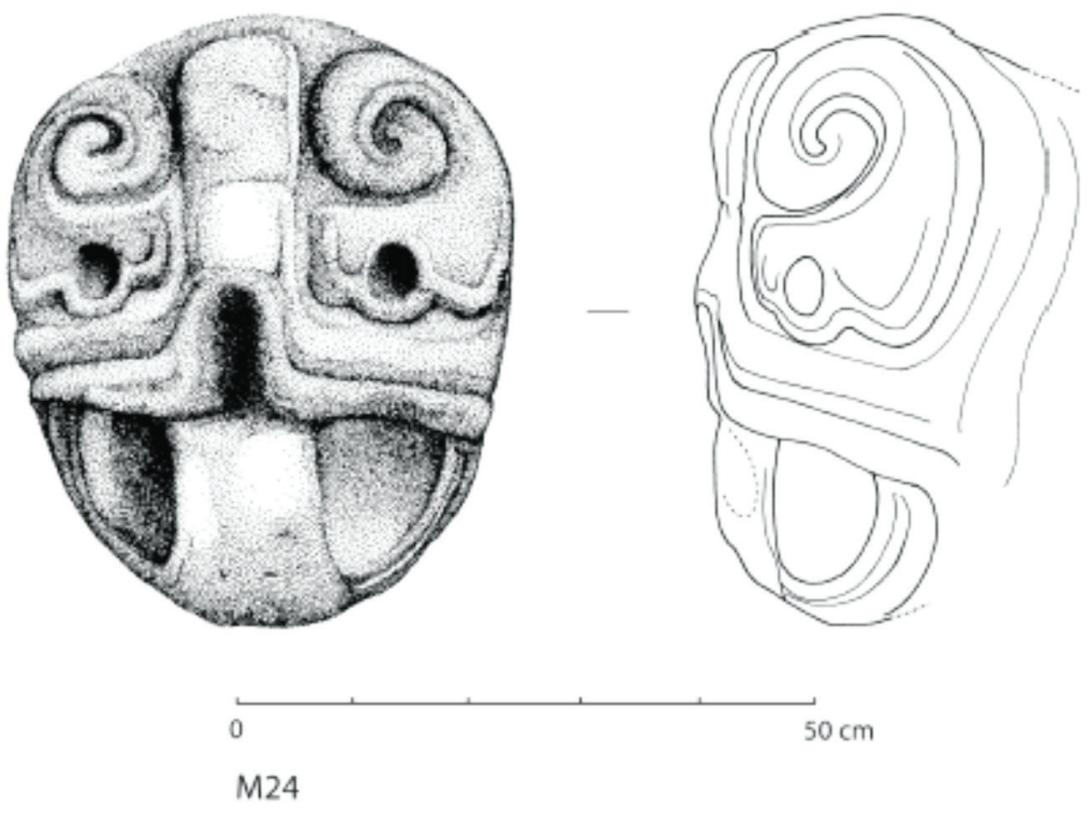

Figura 15. Cabeza de jaguar estilizada, probablemente murciélago, M42, El Salvador (Paredes, 2012, p. 109)

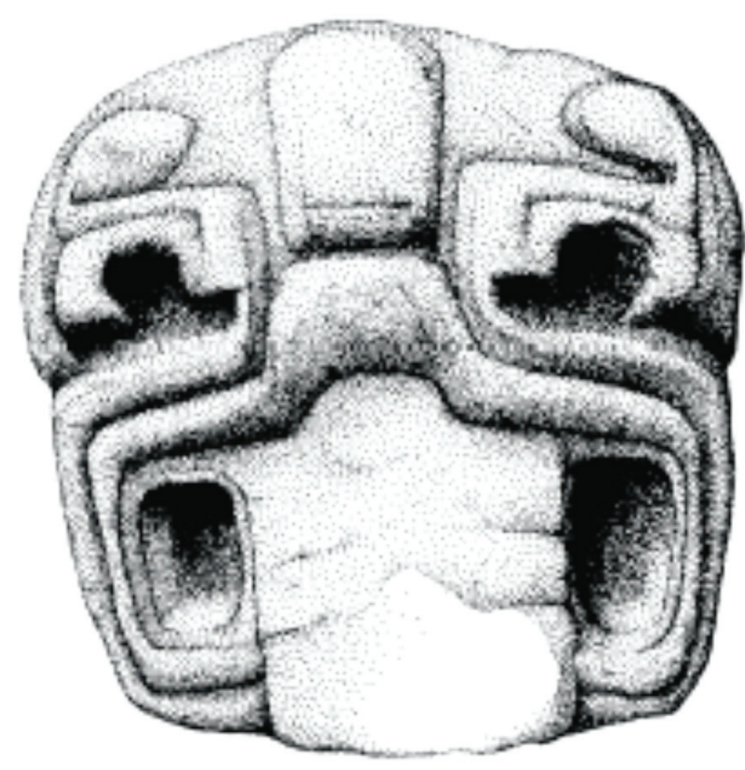


Figura 16. Pectoral de murciélago tairona, siglos XV y XVI

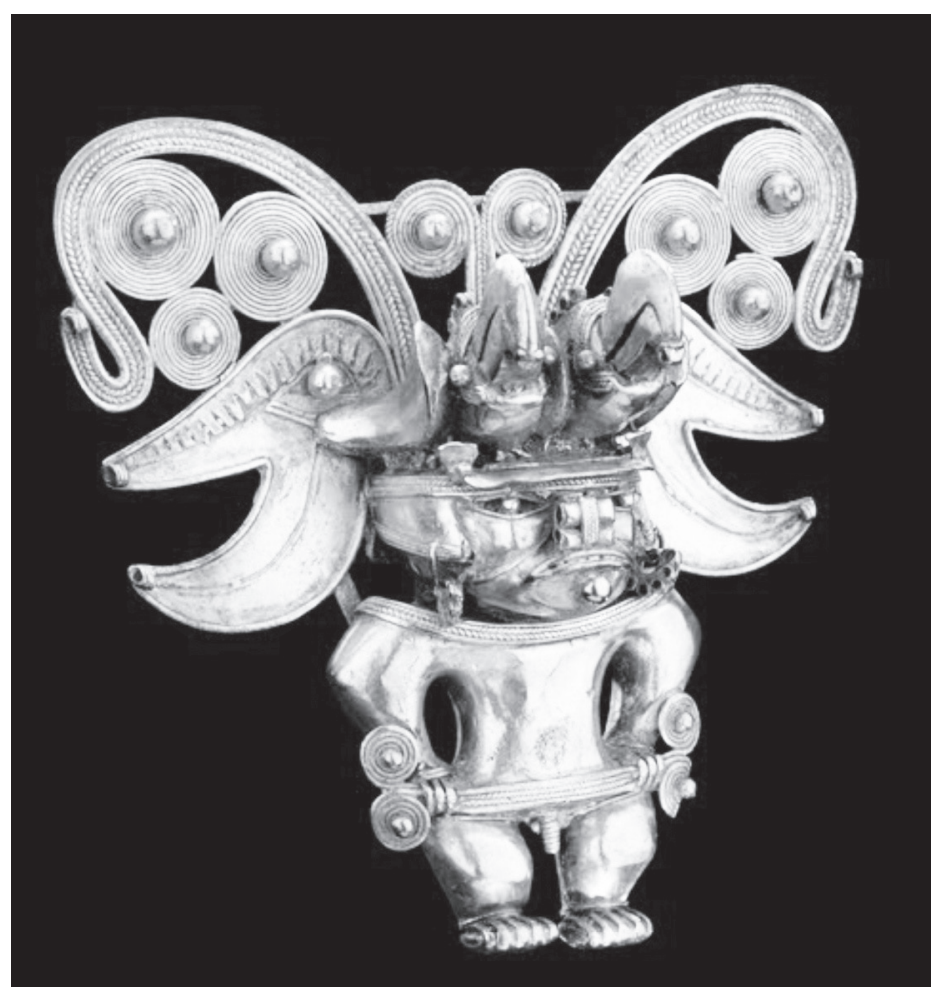

Figura 17. Pectoral de murciélago tairona, siglos XV y XVI, colección privada, USA

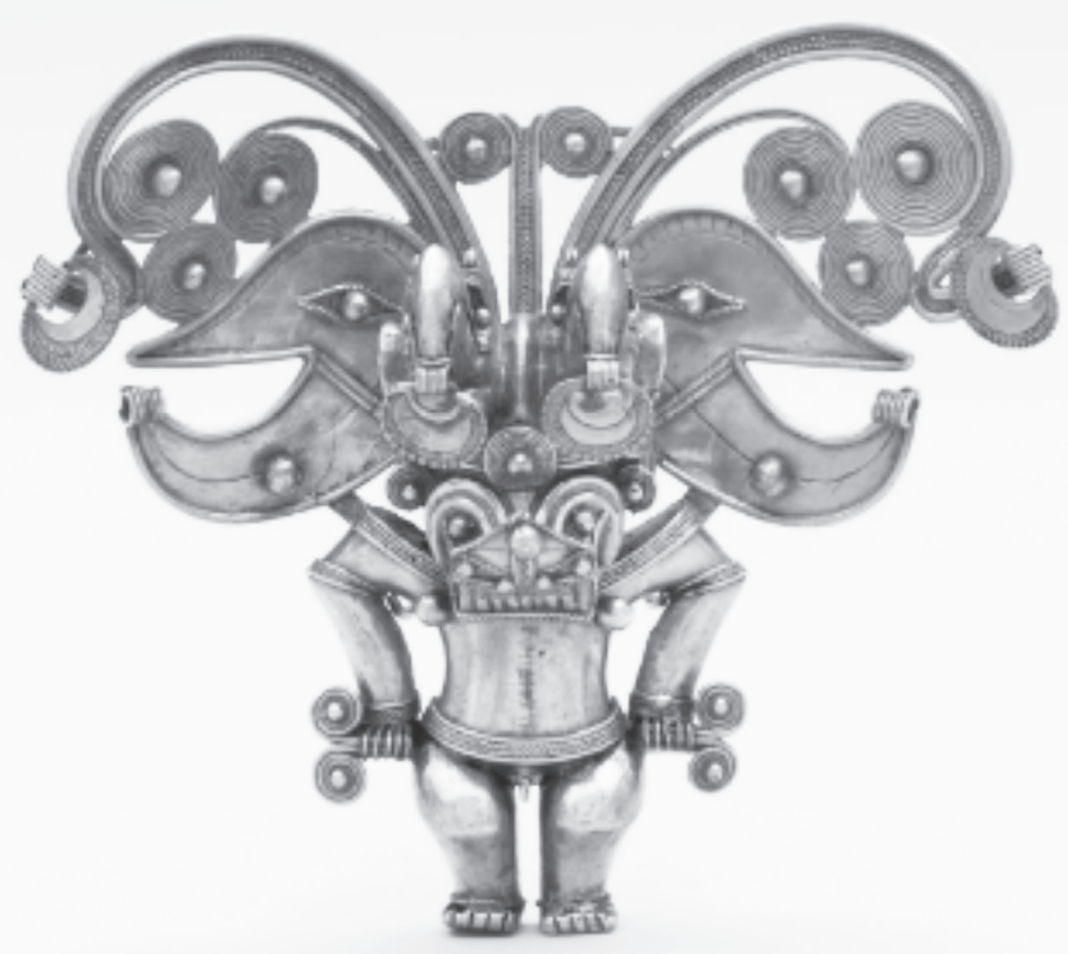


Figura 18. Policromo Nicoya, Costa Rica
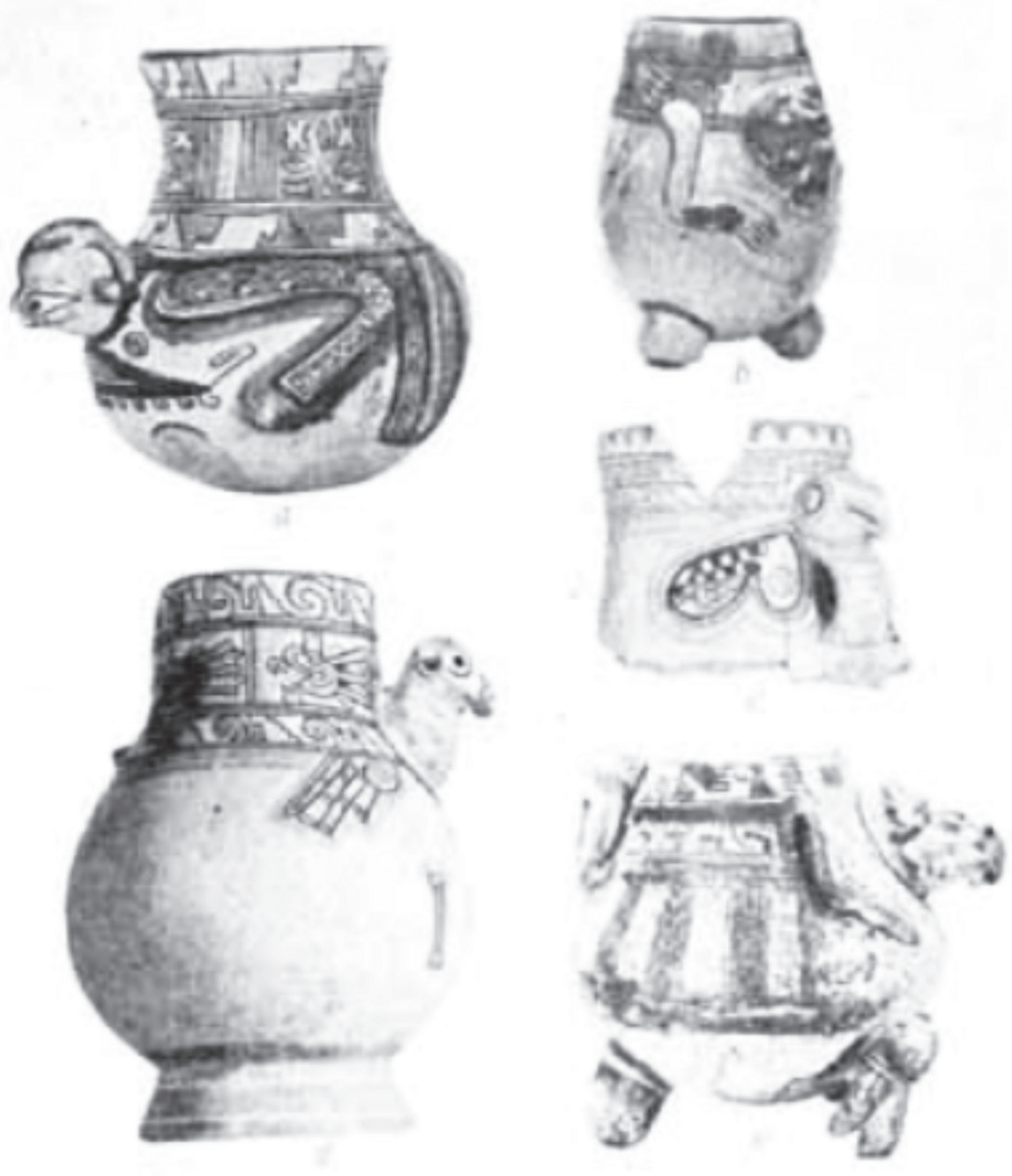

CERAMICA NICOYA POUCROMA

2. - Península de Nicoya, Costa Rica (altura, $17 \mathrm{~cm}$. y $10 \mathrm{~cm}$.). b Tierras altas de Costa Rica (altura $22 \mathrm{~cm}$. ) d - Santa Bárbara, Nicoya, Costa Rica (altura, $25 \mathrm{~cm}$.) - - - Valle de Ulúa. Honduras (altura, $28 \mathrm{~cm}$.) 
Figura 19. Policromo Nicoya, efigie de pavo, Costa Rica
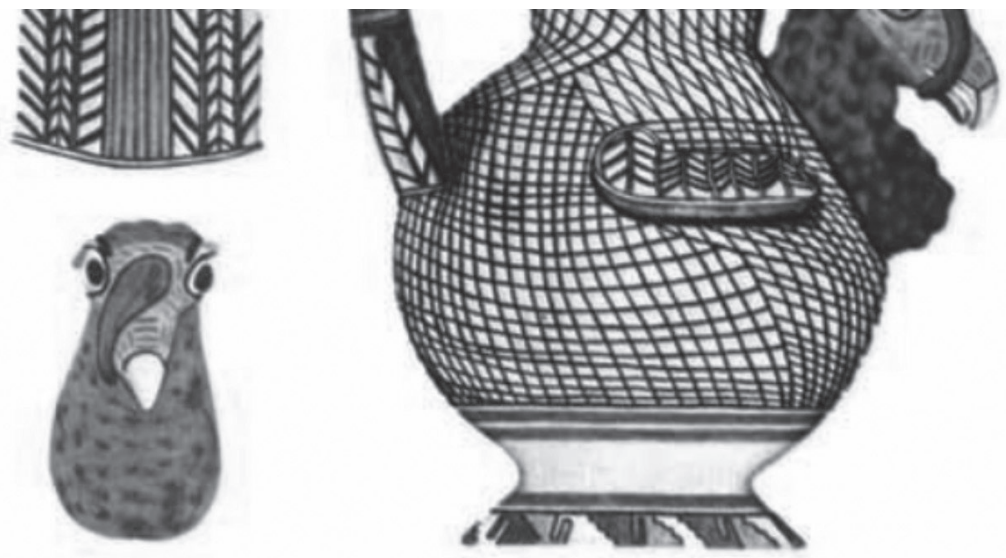

Figura 20. Policromo Nicoya, Costa Rica
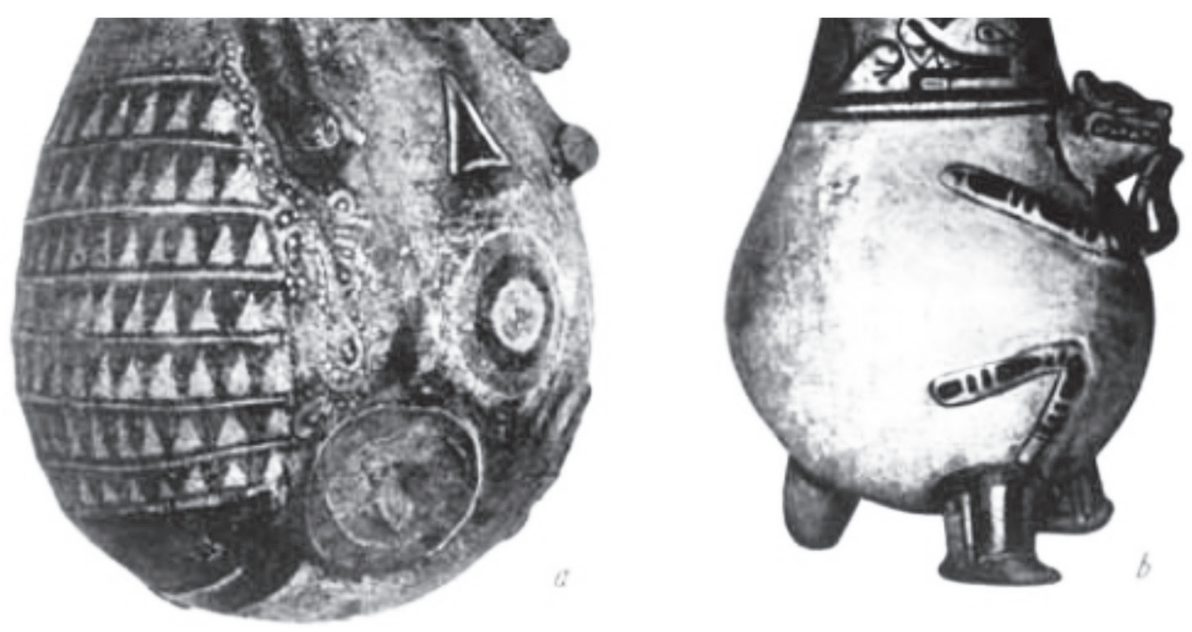

CERAMICA NICOYA POLICROMA. PENINSULA de NICOYA COSTA RICA [Alturs de $\mathrm{b} \times \mathrm{cm}$ ]. 
Figura 21. Figurilla policromo Nicoya, Costa Rica

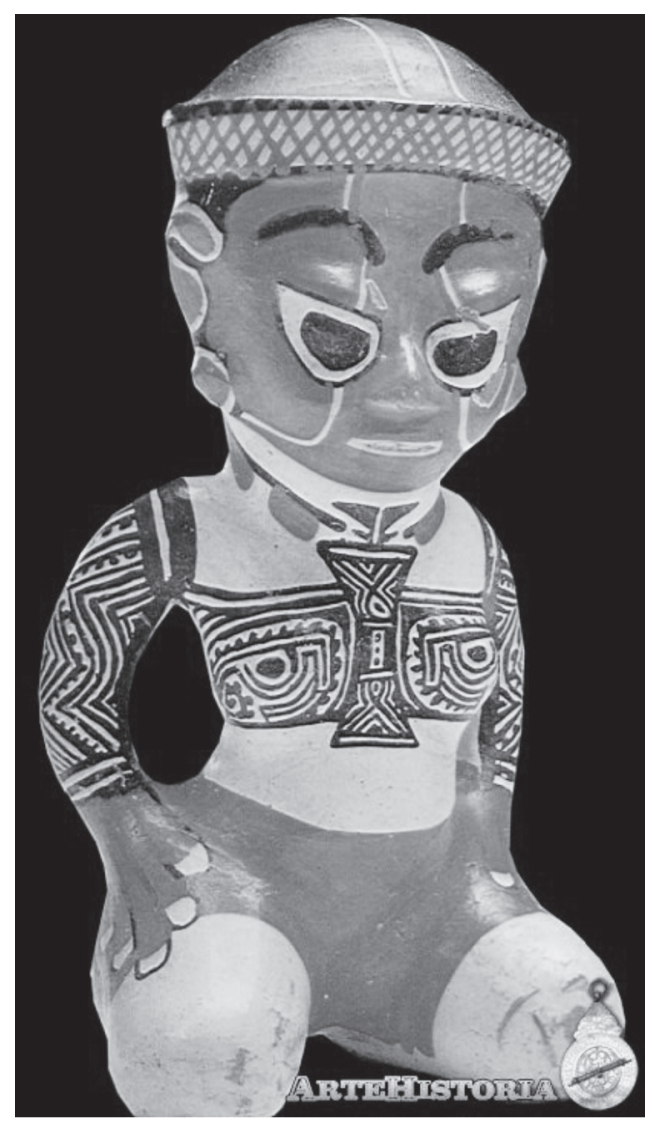

Figura 22. Figurilla policromo Nicoya, Cihuatán, El Salvador, posclásico (Revene \& Olsen Bruhns, 2007, p. 103)
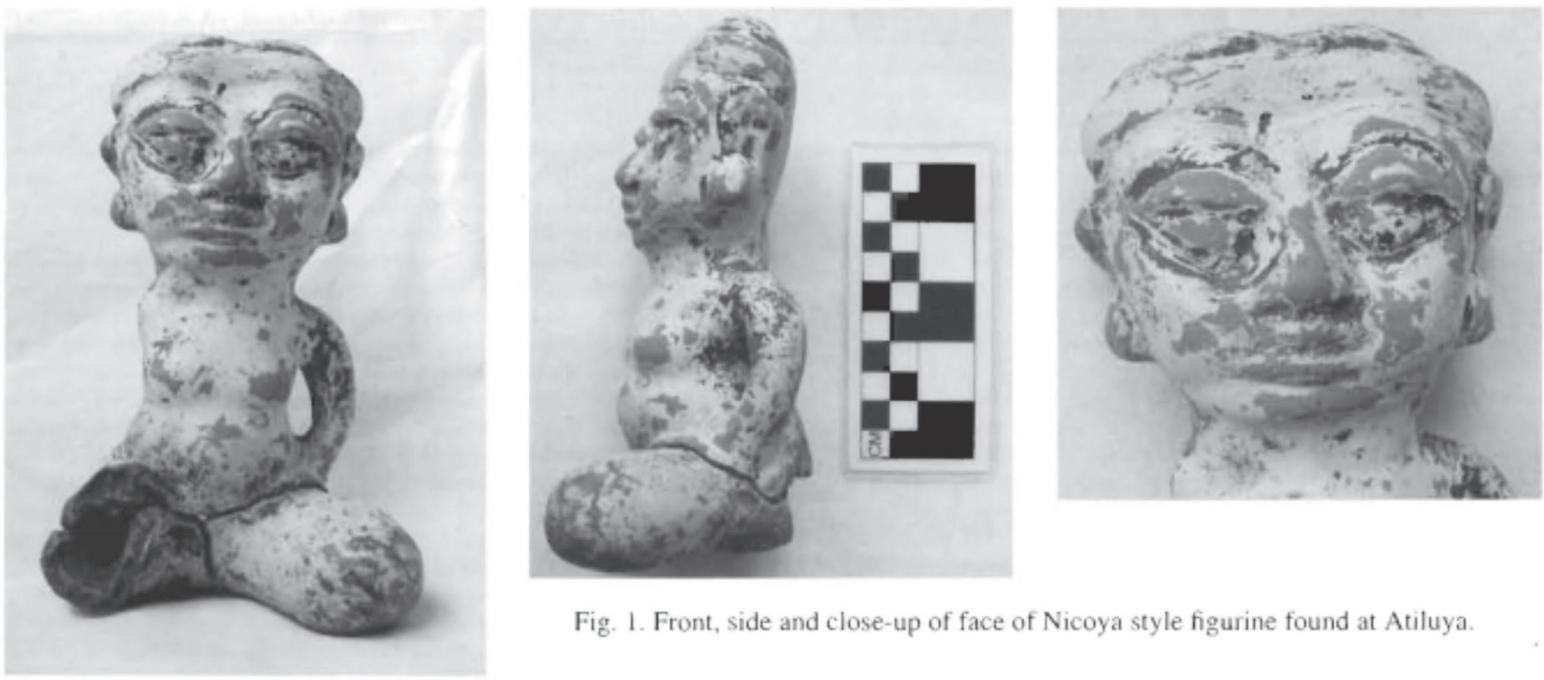

Fig. 1. Front, side and close-up of face of Nicoya style figurine found at Atiluya. 
Figura 23. Policromo Nicoya, El Salvador, posclásico (900-1524 d.C.)

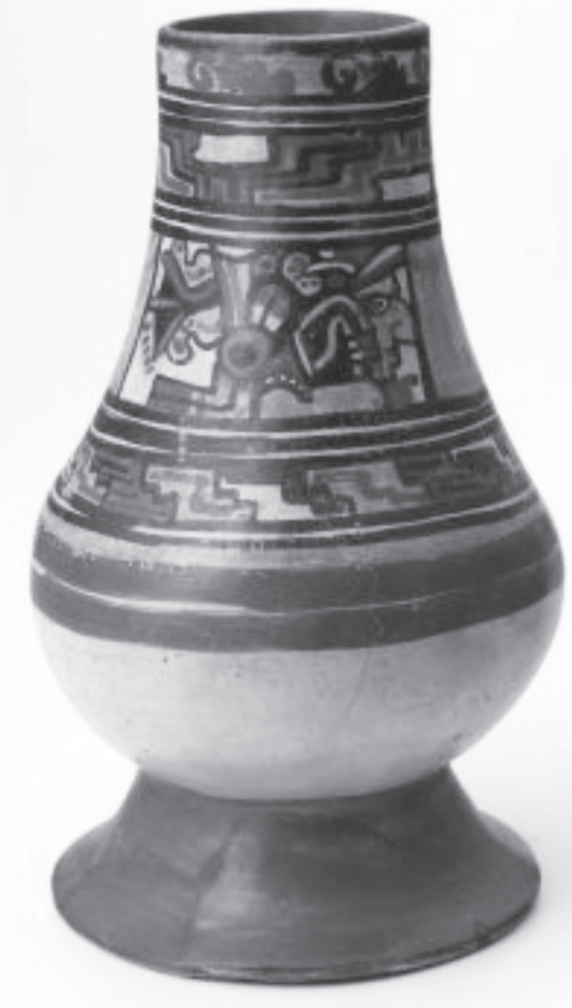

Figura 24. Policromo Nicoya, sitio Cuscatlán, El Salvador, posclásico temprano (Velásquez \& Hermes, 1996)
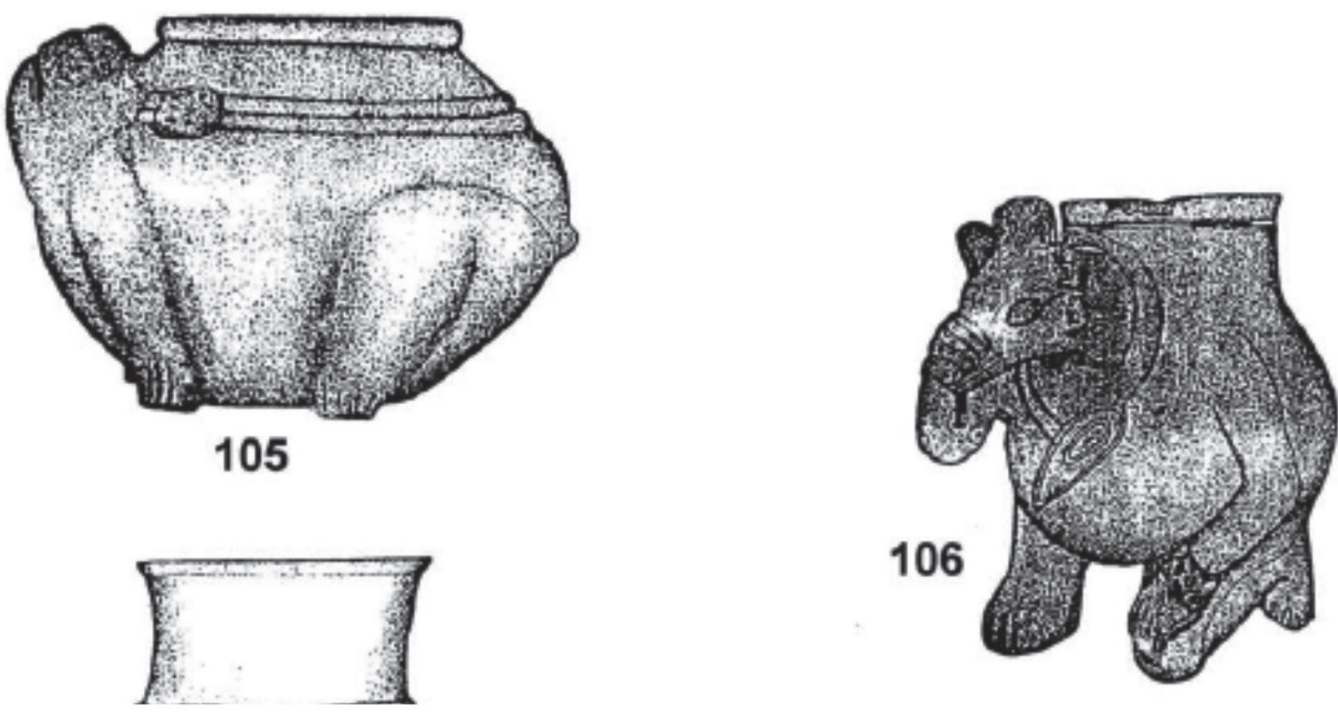
Figura 25. Posibles murciélagos para el Área Intermedia: A) Figura devoradora de cabeza trofeo. Finca 2 corral, Diquís Delta, Costa Rica. B) Devorador de cabeza trofeo, Ullumbé, San Agustín, Colombia. C) asiento con cabezas-trofeo colgantes. Alto de los ídolos, San Agustín, Colombia. D) Figura de ataque felino, La Candela, San Agustín, Colombia. Note las garras antropomorfizadas sosteniendo la cabeza de la figura pequeña, mustia. La segunda figura, que puede ser femenina, se muestra en la pose estándar de respeto 0 devoción (Olsen Bruhns, 1982).
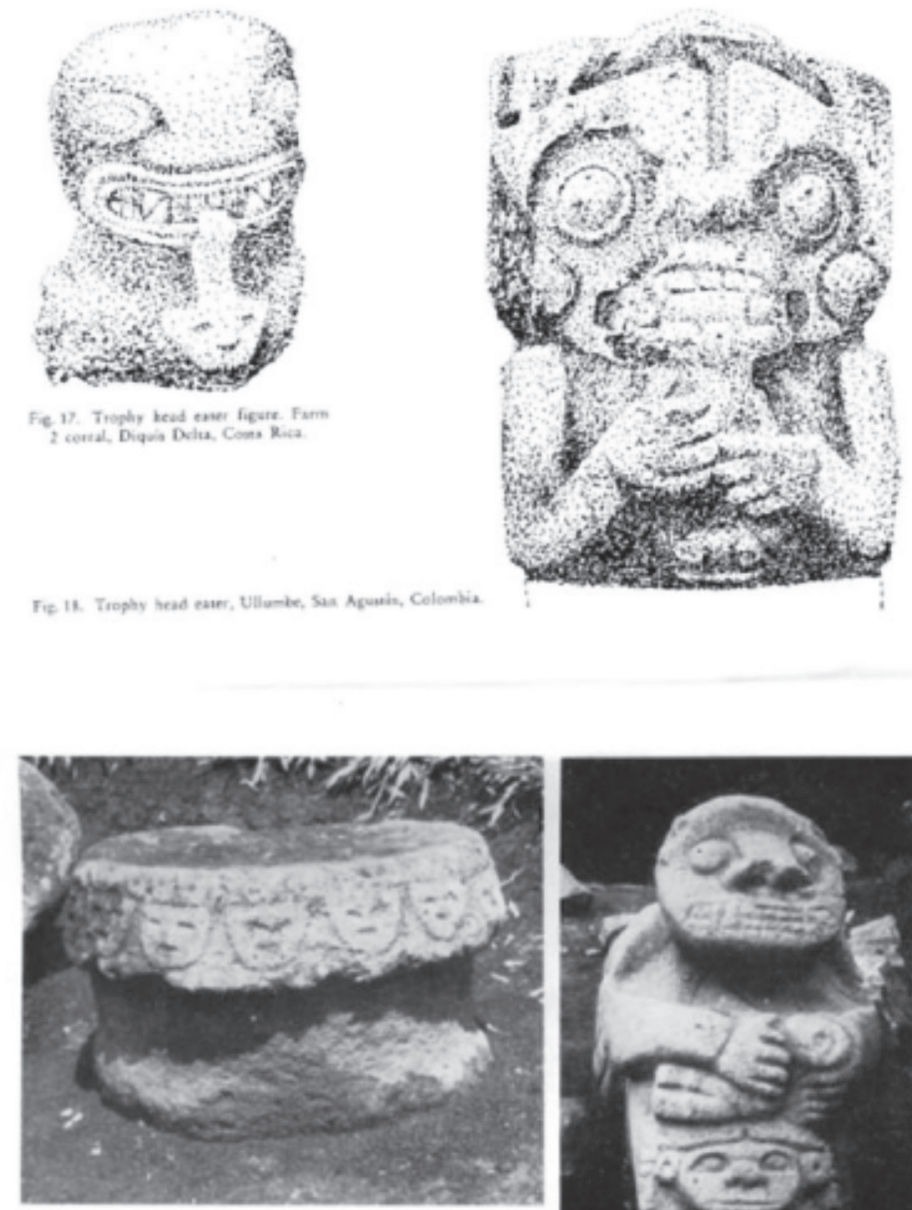

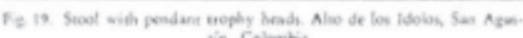

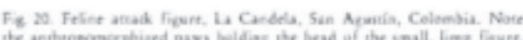

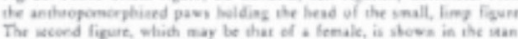

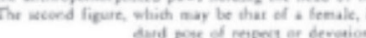

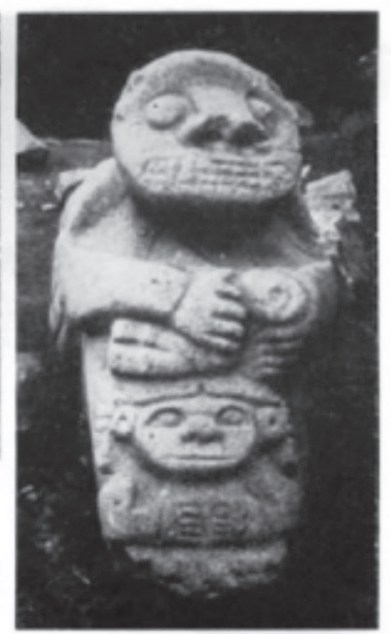


Cuadro 1. Periodización del Área Intermedia según Frederick Lange

\begin{tabular}{|c|l|l|}
\hline Períodos & \multicolumn{1}{|c|}{ Cuadro cronológico del Área Intermedia } & \multicolumn{1}{|c|}{ Años } \\
\hline VI & $\begin{array}{l}\text { Invasión española y sobrevivientes } \\
\text { Metalurgia, oro y cobre }\end{array}$ & 1550 d.C. \\
\hline V & $\begin{array}{l}\text { Cambio y revolución } \\
\text { Fuertes patrones de regionalización } \\
\text { Cerámica policromada }\end{array}$ & 1000 d.C. \\
\hline IV & $\begin{array}{l}\text { Escultura de piedra grabada, jade } \\
\text { Evolución de sociedades de rangos } \\
\text { Comunidades formativas establecidas en algunas } \\
\text { áreas } \\
\text { Fuertes cacicazgos en su mayoría en el sur del }\end{array}$ & $\begin{array}{l}500 \text { d.C. } \\
\text { d.C. }\end{array}$ \\
\hline III & $\begin{array}{l}\text { Introducción de cerámica } \\
\text { Participación en tradición de América nuclear }\end{array}$ & 1000 a.C. \\
\hline II & $\begin{array}{l}\text { Arcaico tropical } \\
\text { Evidencia limitada principalmente a Panamá }\end{array}$ & 4000 a.C. \\
\hline I & $\begin{array}{l}\text { Paleoindio } \\
\text { Evidencia limitada principalmente a Panamá }\end{array}$ & ?- 6000 a.C. \\
\hline
\end{tabular}

Cuadro 2. Secuencia de cambio sociopolítico en las cuencas del Reventazón y Sarapiquí, Costa Rica, según Helms [1979] (Hurtado \& Troyo, 2007).

\begin{tabular}{|l|c|l|l|}
\hline Cronología & \multicolumn{1}{|c|}{ Inicial } & \multicolumn{1}{c|}{ Final } & \multicolumn{1}{c|}{ Nivel de integración sociopolítica } \\
\hline Paleoindio & 9000 a. C. & 7000 a. C. & Sociedad de bandas \\
\hline Arcaico & 7000 a. C. & 2000 a. C. & Sociedad de bandas \\
\hline Formativo medio & 2000 a. C. & 200 a. C. & Sociedad tribal \\
\hline Integración cacical I & 200 a. C. & 800 d. C. & Sociedad cacical redistributiva (tipo Sahlins IIb) \\
\hline Integración cacical II & 800 d. C. & 1500 d. C. & Sociedad cacical absolutista (tipo Sahlins Ila) \\
\hline Colonial & 1500 d. C. & 1821 d. C. & $\begin{array}{l}\text { Sociedad estatal absolutista (reinado e } \\
\text { imperios europeos) }\end{array}$ \\
\hline Republicano & 1821 d. C. & 2008 d. C. & Sociedad estatal democrática y representativa \\
\hline
\end{tabular}

Cuadro 3. Fases culturales según Michael Coe y Baudez para la gran Nicoya (Hurtado \& Troyo, 2007)

\begin{tabular}{|l|c|}
\hline 1) Período bicromo en zonas & 300 a.C.-200 d. C.) \\
\hline 2) Período policromo temprano & $200-800$ d. C. \\
\hline 3) Período policromo medio & $800-1200$ d. C. \\
\hline 4) Período policromo tardío & 1200 d. C. - Conquista \\
\hline
\end{tabular}

